\title{
RESEARCH FOUNDATION REVIEW 2017
}
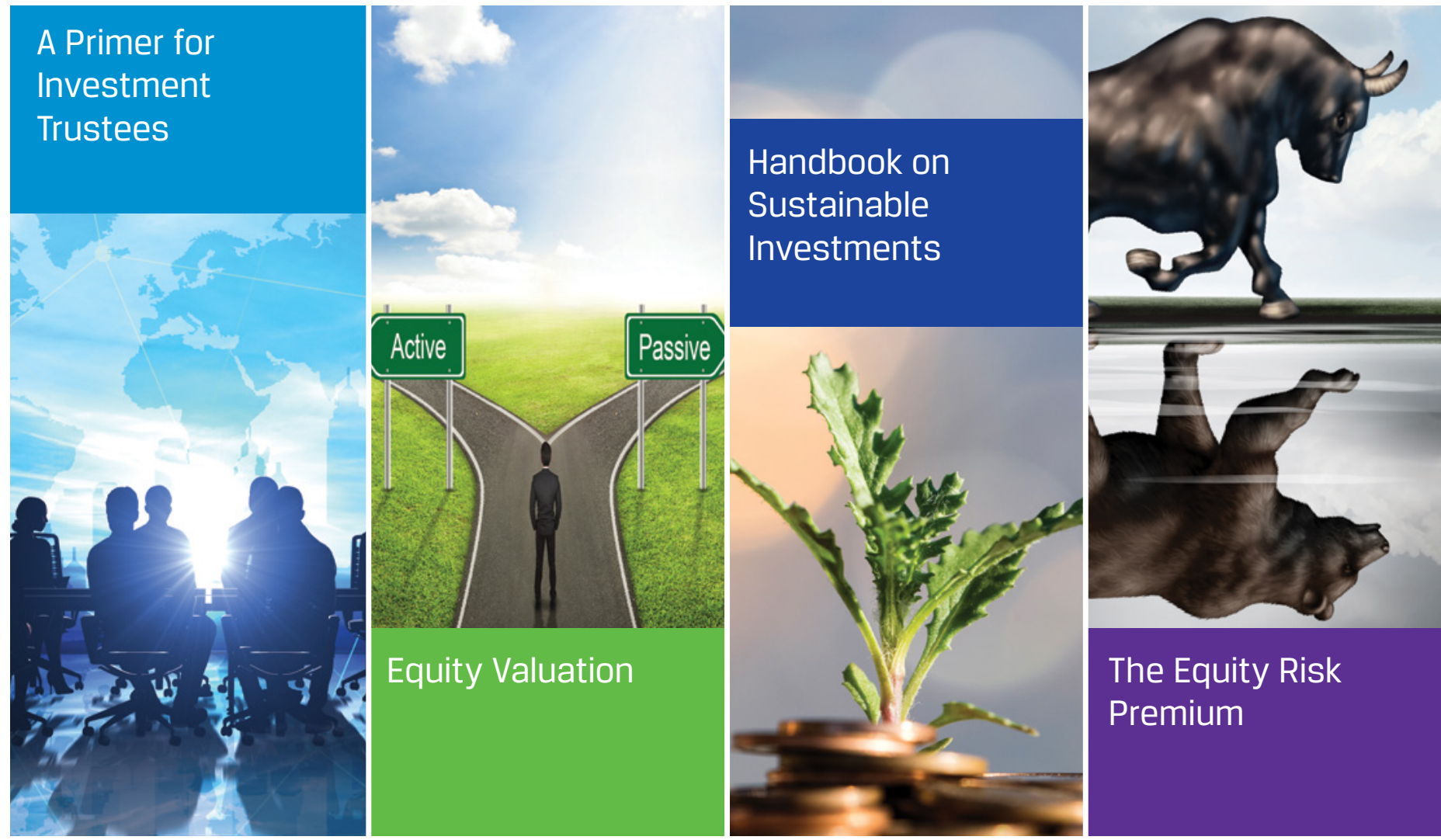


\section{RESEARCH FOUNDATION REVIEW 2017}

- $\mathbb{N}$. CFA Institute Research

Foundation 


\title{
Statement of Purpose
}

\author{
CFA Institute Research Foundation is a \\ not-for-profit organization established to promote \\ the development and dissemination of relevant \\ research for investment practitioners worldwide.
}

Neither CFA Institute Research Foundation, CFA Institute, nor the publication's editorial staff is responsible for facts and opinions presented in this publication. This publication reflects the views of the author(s) and does not represent the official views of CFA Institute Research Foundation.

$\mathrm{CFA}^{\circ}$, Chartered Financial Analyst ${ }^{\circ}$, and GIPS ${ }^{\circ}$ are just a few of the trademarks owned by CFA Institute. To view a list of CFA Institute trademarks and the Guide for the Use of CFA Institute Marks, please visit our website at www.cfainstitute.org.

๑) 2018 CFA Institute Research Foundation. All rights reserved.

No part of this publication may be reproduced, stored in a retrieval system, or transmitted, in any form or by any means, electronic, mechanical, photocopying, recording, or otherwise, without the prior written permission of the copyright holder.

This publication is designed to provide accurate and authoritative information in regard to the subject matter covered. It is sold with the understanding that the publisher is not engaged in rendering legal, accounting, or other professional service. If legal advice or other expert assistance is required, the services of a competent professional should be sought.

ISBN 978-1-944960-41-4 


\section{CONTENTS}

\section{THE YEAR IN REVIEW}

Learning from History: A Message from Paul Smith, CFA .................................... 2

Message from the Research Foundation Chair ................................................... 4

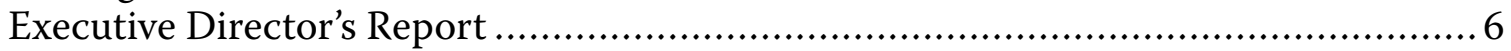

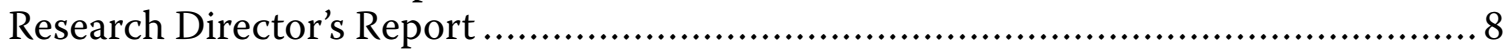

\section{BOOK SUMMARIES}

A Primer for Investment Trustees: Understanding Investment Committee

Responsibilities....

by Jeffery V. Bailey, CFA, and Thomas M. Richards, CFA

Equity Valuation: Science, Art, or Craft?....

by Frank J. Fabozzi, CFA, Sergio M. Focardi, and Caroline Jonas

Handbook on Sustainable Investments: Background Information and Practical

Examples for Institutional Asset Owners

by Swiss Sustainable Finance

\section{LITERATURE REVIEW SUMMARIES}

The Equity Risk Premium: A Contextual Literature Review

by Laurence B. Siegel

\section{BRIEFS SUMMARIES}

Impact of Reporting Frequency on UK Public Companies

by Robert C. Pozen, Suresh Nallareddy, and Shivaram Rajgopal

Financial Risk Tolerance: A Psychometric Review

by John E. Grable

FinTech and RegTech in a Nutshell, and the Future in a Sandbox

by Douglas W. Arner, Jànos Barberis, and Ross P. Buckley

New Vistas in Risk Profiling

by Greg B. Davies

Asian Structured Products.

by Angel Wu and Clarke Pitts 


\section{MULTIMEDIA SUMMARIES}

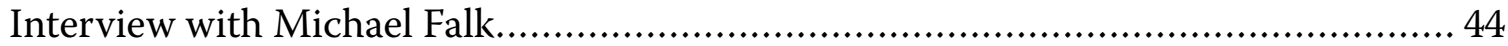

\section{WORKSHOP FOR THE PRACTITIONER SUMMARIES}

Let's All Learn How to Fish...to Sustain Long-Term Economic Growth 46

Financial Market History: Reflections on the Past for Investors Today

\section{AWARDS AND RECOGNITION}

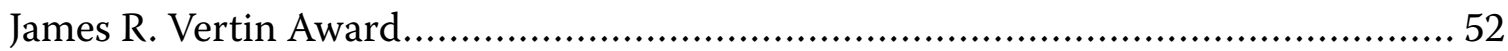

Research Foundation Society Award .............................................................. 54

Research Foundation Leadership Circle......................................................... 57

\section{RECENT PUBLICATIONS}

Recent Publications from the Research Foundation Archive .................................6 60

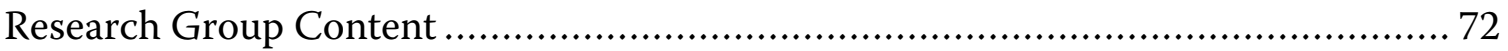




\section{THE YEAR IN REVIEW}




\title{
LEARNING FROM HISTORY: A MESSAGE FROM PAUL SMITH, CFA
}

\author{
Paul Smith, CFA \\ President and CEO \\ CFA Institute
}

Winston Churchill once said, "Want of foresight, unwillingness to act when action would be simple and effective, lack of clear thinking, confusion of counsel until the emergency comes, until self-preservation strikes its jarring gong-these are the features which constitute the endless repetition of history." ${ }^{1}$

From his statement, we can derive that we have a lot to learn from history; we should use it as a guide to avoid mistakes and improve the likelihood of future success. Since the 2008 financial crisis, there has been a resurgence of interest in economic and financial history among investment professionals, and rightfully so. As an industry, we have much to learn from our financial past, and doing so can help us navigate future challenges and assist investors in more effectively weathering the ups and downs. The CFA Institute Research Foundation serves as a critical source for acquiring that knowledge-both historical and forward looking.

The Research Foundation sponsors, publishes, and distributes innovative research on topics that contribute to or improve global investment practices and the CFA Institute Global Body of Investment Knowledge $\left(\mathrm{GBIK}^{\circ}\right)$, which is used by investment professionals all over the world. During the last 53 years, the Research Foundation has played a vital role in educating investment professionals by providing comprehensive, highquality, practical research they can apply to the work they do each day.

One of the recent projects funded by the Research Foundation was the writing and publication of Financial Market History: Reflections on the Past for Investors Today, which brings together knowledge and insight from many of the world's leading academics and investment professionals about the history of financial markets and what today's practitioners need to know. It examines long-run series data on various asset classes, the history of the world's major stock markets, market booms and bubbles, and innovations in modern finance, among other topics.

Of course, this book is just one of many projects recently funded by the Research Foundation to help enrich the global investment community's collective knowledge. In

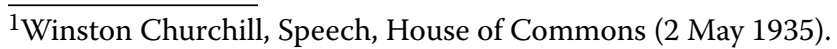


fact, all Research Foundation books published since 1997 are available online, providing instant access to in-depth research on industry topics ranging from the historical to the cutting edge. Through research, at least in part, we are developing investment professionals who can better serve investors.

In addition to published works, the Research Foundation delivers research through inperson conferences and recognizes excellence in contributions to the global investment community through the James R. Vertin Award. Research produced by the Research Foundation is often widely quoted and referenced for years because it is led and conducted by highly qualified, passionate experts who are at the top of their field and often ahead of their time.

Through research, we can acquire the knowledge of where the industry has been and where it is heading. This education is one of the most essential tools we can use to prepare and position ourselves to be the most trusted and well-respected investment professionals anywhere and, most importantly, to serve investors with unparalleled competence, integrity, and credibility. 


\title{
MESSAGE FROM THE RESEARCH FOUNDATION CHAIR
}

\author{
Joachim Klement, CFA \\ Chair \\ CFA Institute Research Foundation
}

As we enter 2018, it is hard to believe that 10 years have passed since the global financial crisis began. November 2007 marked the high point for stock markets before their $50 \%$ drop and the near collapse of the global financial system. Many of us can still vividly remember the anxiety and uncertainty that pervaded during the crisis. Given that a typical financial industry career lasts about 30 years these days, however, we also must be aware that about one-third of all financial analysts, brokers, traders, and financial advisers today were not yet professionals during the financial crisis, which means that they have not yet experienced a recession or a major stock market decline in their careers.

Yet, CFA charterholders, CFA Program candidates, and the many advisers not associated with CFA Institute strive to provide the best advice for our clients. High-quality financial research and information is a key prerequisite for those who have to prepare themselves and their clients for the future. If you have never experienced a bear market firsthand, you can gain a long-term perspective by reading about the fundamentals of equity market valuation or your fiduciary duties as an investment trustee. Furthermore, even if you experienced the global financial crisis professionally, the unprecedented monetary policy measures of central banks have taken us into new territory that is difficult to understand without high-quality research. And if you work in wealth management and have to assess the behaviour of private investors in good and bad times, it may be time to brush up your knowledge on risk profiling to better assess your clients' propensity and willingness to take risks. Preparing yourself for the possible end of a bull market makes a lot of sense when the recovery enters its ninth year.

In the 53 years since its inception in 1965, the CFA Institute Research Foundation has strived to accomplish its mission of providing independent, high-quality research that helps investment professionals effectively fulfil their duties with prudence, loyalty, and care. Governed by an all-volunteer group of trustees with extensive investment experience from all over the world and in a broad variety of disciplines, staffed with a small group of dedicated and hard-working employees, and supported by CFA Institute, the Research Foundation has helped advisers and investors navigate the uncharted waters we have been in since the end of the global financial crisis. Through its many publications and its independent research, this organisation has guided its many thousands of readers and their clients. 
Our books, published both digitally and in print, cover important topics that shape the investment profession and our industry. Written by academics and practitioners in an accessible language without jargon, each book analyses a specific topic in depth. Written without bias or commercial interests, these publications allow readers to learn about the advantages and pitfalls of sustainable investing, the art and craft of equity valuation, or steps to become a better investment trustee-to name just the latest topics covered by these books. Because they are written by independent experts in the field, fads and fashions that are all too common in our industry may get debunked while risks and opportunities are discussed in a fair and balanced way. It is this independence of research that provides the most important benefit to our readership. Working with private investors and institutional investors alike, I frequently am confronted with questions about the efficacy of a new product or investment approach, and CFA Institute Research Foundation publications have helped me time and again to fulfil my fiduciary duty to my clients, answer their questions in a concise and transparent way, and enable them to make better decisions for their investments.

When I could help my clients avoid crucial financial mistakes because of an analysis I read from the Research Foundation, or when I could educate clients by handing them a copy of our primer for investment trustees, or when these educational efforts not only increased the bond between us but also helped my clients better understand their tasks as trustees or their challenges as investors-these are the moments that make me proud to be their adviser. In short, what we aim to do with our publications is to make our readers look good and help them differentiate themselves from their competitors.

Of course, not every topic can or should be covered in a book. Many of our readers are restricted for time, and some topics are too specialised to warrant an extensive analysis. We have thus started to provide research in shorter, easier-to-digest formats. Today, we publish literature reviews and webinars, and we organise a high-class workshop at the CFA Institute Annual Conference that is always well attended and well received by participants. To be able to cover topics in a concise and timely fashion, we also publish Research Foundation briefs, relatively short papers of 5 to 15 pages that cover a crucial topic for practitioners and can be read in less than half an hour. Throughout 2017, we have addressed such important issues as FinTech, RegTech, and their impact on the financial industry; analysed the structured product market in Asia; and continued our series of briefs on risk profiling with two instalments covering psychometric techniques and an outlook of the future of risk profiling.

This work has helped many of you and your peers improve in your chosen professions. On behalf of the Research Foundation, I thank you for your support not only as readers and advocates of our publications but also through your generous donations. The Research Foundation is supported by CFA Institute but depends on donations from our readers and authors to fulfil its mission. By helping us with your donation, you are helping the Research Foundation continue and expand its mission in the future. 


\section{EXECUTIVE DIRECTOR'S REPORT}

\section{Bud Haslett, CFA \\ Executive Director \\ CFA Institute Research Foundation}

Building on previous gains, the CFA Institute Research Foundation had another stellar year in 2017, with content published on FinTech, trustee education, the equity risk premium, risk profiling, and many other topics of interest to global investment professionals.

This year, Research Foundation publications included content on some niche regional topics-for example, Asian structured products and UK public company reporting frequency. The short format of the Research Foundation briefs makes publication of such content possible, and we look forward to publishing pieces on capital markets in Latin America and the French pension system in the near future. Even though this content focuses on regional issues, the astute global investment professional will find much knowledge to gain and apply to other markets in these short research pieces.

One of the challenges we face at the Research Foundation is that the target market for our audience is so diverse. The needs of a 55-year-old private wealth adviser from Seattle or Lucerne differ substantially from those of a 25-year-old entry level portfolio manager from Shanghai or Lagos. We do not strive to have every investment professional read every piece of our content. Instead, we strive for every piece of Research Foundation content to be high quality so that readers will find value in the content relevant to them. In other words, if you choose to read it, you will get value from it. In that way, we can best serve you, the global investment professional, in a world of innumerable content choices.

This year, the Research Foundation achieved many firsts. We were honored to submit our first content on the Asia-Pacific Research Exchange (ARX) and very much look forward to contributing new content to this exciting research platform in years to come. In addition, for the first time, we won the best investment paper award at the research platform Savvy Investor. Our book on financial market history was one of the most downloaded publications and was called "a compelling tour de force!" by the editors. We also achieved a first on the donation front: We received contributions from more than 10,000 global investment professionals for the fiscal year. This broad support from a diverse group of CFA Institute members and others is surely a sign we are on the right path.

Thanks to additional funding from CFA Institute, the Research Foundation was able to achieve yet another first as we translated our book on manager selection into Mandarin. We are close to completing other translations of Research Foundation 
content, including upcoming releases of A Comprehensive Guide to Exchange-Traded Funds in Mandarin and Portuguese. The additional funding also allowed us to expand our Research Foundation author speaker program to include a tour of multiple CFA societies instead of just one-off events that revolve around speaker travel plans. These translations and speaker tours, in addition to the Research Foundation's past and present content, will be increasingly important as CFA Institute embarks on the exciting new society initiatives of the future.

Because of our content's popularity, we sent record numbers of complimentary Research Foundation books to CFA societies around the globe and were delighted to work with nearly 100 different societies during the year. We were also pleased to present the Research Foundation Society Award to CFA Society Brazil, CFA Montréal, and CFA Society New York during the Society Leadership Conference. Congratulations to these societies for their great work on their websites, content, and events as they join the other societies that have won the award.

The Research Foundation was also delighted to welcome society presidents Mauro Miranda, CFA (Brazil), and Sophie Palmer, CFA (Montreal) to serve on the Research Foundation board of trustees. Both are already making valuable contributions, with Mauro editing the new Latin American capital markets brief and Sophie serving as chair of the planning and marketing committee. We wish them well for the future.

Because of an organizational change in 2017, the Research Foundation was joined by the Financial Analysts Journal ${ }^{\otimes}$ and the Future of Finance in a new research area within CFA Institute. We are delighted to be a part of the group and look forward to working closely with both teams. We have included overviews for the Financial Analysts Journal and Future of Finance in this Research Foundation review.

Finally, I would like to give thanks to the wonderful Research Foundation board and our board chair, Joachim Klement, CFA; our research director, Laurence Siegel; the Research Foundation coordinator, Jessica Critzer; our treasurer, Kim Maynard; our authors; and all the amazing CFA Institute staff, board members, and leadership team for all you do to make the Research Foundation possible. Thanks, too, to the tens of thousands of donors and readers of our content who make it all worthwhile. It is my deepest honor to serve as executive director, and I look forward to a long and successful future for the Research Foundation. 


\title{
RESEARCH DIRECTOR'S REPORT
}

\author{
Laurence B. Siegel
}

Gary P. Brinson Director of Research

CFA Institute Research Foundation

In 2017, the CFA Institute Research Foundation published three new books, a Chinese translation of an existing book, the Research Foundation Review 2016, a literature review, and five briefs.

\section{Books}

\section{Jeffery V. Bailey, CFA, and Thomas M. Richards, CFA, A Primer for Investment Trustees: Understanding Investment Committee Responsibilities}

One of the biggest impacts the Research Foundation can have is to improve the quality of governance of investment funds, including pension, endowment, foundation, and sovereign wealth funds. Many trustees of such funds have good intentions and intellectual curiosity but limited knowledge of the mechanics and theory of investing. In this new and expanded edition of $A$ Primer for Investment Trustees, originally published in 2011, Jeffrey Bailey and Thomas Richards provide a knowledge base and advice on process and structure for fund trustees seeking to build a portfolio of asset classes and/ or managers for their institutions. The primer includes a new section on defined contribution plans, the fastest-growing component of retirement plans. This book, applied more broadly, also has the potential to improve the management of self-directed retirement accounts managed with the help of financial advisers.

\section{Frank J. Fabozzi, CFA, Sergio M. Focardi, and Caroline Jonas, Equity Valuation: Science, Art, or Craft?}

The trio of Frank Fabozzi, Sergio Focardi, and Caroline Jonas has produced an elucidating series of survey-based books on various topics of interest to institutional asset managers. This, their fifth, focuses on the ways that equity analysts determine fair prices for the securities they study. The authors begin by distinguishing absolute from relative valuation and comparing various valuation methods using responses from the surveyed analysts. They then consider hard-to-value equities, including initial public offerings and privately held companies. A section considers the possibility that equity prices have been distorted upward by central bank actions in the current decade. 
Finally, the authors cover new tools for equity valuation, including artificial intelligence and the use of big data. As with all of the Fabozzi, Focardi, and Jonas books, the authors rely heavily on knowledge and opinion expressed by the survey participants "in their own words."

\section{Swiss Sustainable Finance, Handbook on Sustainable Investments: Background Information and Practical Examples for Institutional Asset Owners}

In the past decade, environmental, social, and governance (ESG) criteria and goals have gone from being a niche interest to a mainstream movement, with massive demand from pensions, foundations, churches, and individual investors. In Handbook on Sustainable Investments, we present a Swiss perspective, thanks to a collaboration with Swiss Sustainable Finance, which, along with CFA Society Switzerland, translated the publication into English. The book begins by categorizing sustainable investments along methodological lines-for example, exclusion of disfavored securities, integration of ESG criteria into conventional security analysis, exercising voting rights, shareholder engagement with companies, and so forth. The book then considers ESG investing across asset classes, including alternatives, and makes note of special ESG goals, such as climate change mitigation. Principles of sustainable investing are illustrated through extensive case studies representing different types of institutions and investment approaches.

In addition to these monographs, the Research Foundation translated into Chinese a 2013 book by Scott Stewart, Manager Selection. The book addresses issues raised by the challenge of selecting winning active managers in an environment where it is impossible for all or even most of these managers to beat the "market" or their benchmarks, and as predicted, many do not. Therefore, manager selection relies on both art and science to achieve successful results.

\section{Literature Reviews}

\section{Laurence B. Siegel, The Equity Risk Premium: A Contextual Literature Review}

In this review, I begin with the establishment of an equity risk premium concept in pre-modern portfolio theory days. I then note that the capital asset pricing model of William Sharpe (and others) calls for an estimate of the equity risk premium, a requirement filled by the research of Roger Ibbotson and Rex Sinquefield in the 1970s and 1980s. The Research Foundation published two of their seminal works (1982 and 1989, respectively), which rely on the proposition that the future equity risk premium will, on average, equal the premium achieved in the past. As markets rose during the 1990s, 
various versions of the dividend discount model became more popular for estimating the equity risk premium, largely because they produced moderate forecasts of future returns, appropriate for the markets' then-high levels. These models stood in contrast to the high forecasts produced by the future-equals-past approach. In the 2000s and 2010 s, research on the equity risk premium has become more integrative, drawing on insights from all of the threads previously identified.

\section{Briefs}

\section{Robert Pozen, Suresh Nallareddy, and Shivaram Rajgopal, "Impact of Reporting Frequency on UK Public Companies"}

Motivated by a widespread concern about short-termism in corporate management, Robert Pozen, Suresh Nallareddy, and Shivaram Rajgopal studied the effects of changes in required financial reporting frequency for companies in the United Kingdom. They hypothesized that frequency of reporting might affect levels of corporate investment, analyst coverage, and the accuracy of analysts' earnings forecast. Because UK regulations increased the frequency of required reporting from quarterly to semiannually in 2007 and then reversed the decision in 2014, a natural experiment was made possible. With the increase in frequency, the authors found no effect on investment but an increase in analyst coverage and forecast accuracy. The authors conclude that "moving from quarterly to semiannual reporting is not an effective remedy for undue corporate emphasis on short-termism."

\section{Angel Wu and Clarke Pitts, "Asian Structured Products"}

Structured products are usually defined as investment instruments that deliver the return on some equity or fixed-income index, usually with options added that guarantee return of principal or provide some other benefit. In Asia, structured products are very important for individual investing and have a different character from structured products in other regions. Angel Wu and Clark Pitts's brief reviews these instruments.

\section{Greg B. Davies, "New Vistas in Risk Profiling"}

In this brief, Greg Davies distinguishes risk tolerance, behavioral risk attitudes, and risk capacity. They are all different, and the differences are important for advisers trying to understand the unique approach to risk taken by each client. For example, the author states that "the risk investors are willing to take might not be risk they are able to take"; one would be ill-advised to encourage a client to take unsuitable risks just because she wants to. It is thus imperative to make this distinction. "New Vistas in Risk Profiling" is one of our five-part series of briefs on risk profiling for individual investors. 


\section{Douglas W. Arner, Jànos Barberis, and Ross P. Buckley, "FinTech and RegTech in a Nutshell, and the Future in a Sandbox"}

In a provocative and informative brief, Douglas Arner, Jànos Barberis, and Ross Buckley review recent technological and regulatory changes in financial markets and the provision of financial services. Although FinTech has been a buzzword for some time, regulators have, out of necessity, responded to innovation in financial technology by developing their own technologies for monitoring and supervising financial institutions. The authors focus on the newer changes. The "sandbox" refers to a tradition in technology whereby innovators create a space for unstructured "play" in the hope of leading to further, unanticipated innovation.

\section{John E. Grable, "Financial Risk Tolerance: A Psychometric Review"}

In this element of our five-part series on risk profiling, John Grable uses psychometric techniques-derived from the science of measuring mental ability, personality, and attitudes-to improve the quality of risk profiling in practice. The brief relies on classical test theory, which is concerned with the validity and reliability of psychological test results. (For example, the results of intelligence tests can vary considerably across time for any given test-taker, so intelligence is estimated statistically rather than measured with perfect accuracy.) The author applies these concepts to measuring various dimensions of an individual's approach to financial risk taking, using examples from practice.

\section{Future Work}

In 2018, the Research Foundation expects to receive manuscripts on the relationship between the popularity and returns of stocks, investment governance for fiduciaries, restoration of the dynamism of the economy, and the pension crisis, as well as a primer on alternative investments. At least three of these books will be published by the end of the year. We will also publish briefs, as well as a literature review on the quantitative analysis of equities. 



\section{BOOK SUMMARIES}




\section{A PRIMER FOR INVESTMENT TRUSTEES: UNDERSTANDING INVESTMENT COMMITTEE RESPONSIBILITIES}

\author{
by Jeffery V. Bailey, CFA, and \\ Thomas M. Richards, CFA
}

The genesis of $A$ Primer for Investment Trustees was our realization that remarkably few educational resources are available for people charged with the oversight of pools of investment assets with long-term beneficial missions. That notion seemed counterintuitive to us. After all, there are many thousands of investment funds and hundreds of thousands of individuals around the world who bear the responsibility of overseeing investment programs that amount to tens of trillions of dollars. Surely, we thought, given the importance that these oversight bodies play, there would be volumes of introductory and advanced discussions on how to effectively perform as an investment trustee. Yet, with the exception of articles narrowly focused on certain fiduciary responsibilities that may vary from country to country, training materials for investment trustees are in amazingly short supply. That shortage stands in stark contrast to the vast literature available to professionals who are hired to directly manage the investment assets. Thus, we were drawn to the idea of producing a concise, understandable book directed primarily to neophyte investment trustees.

The current book is the second edition of $A$ Primer for Investment Trustees, first published in 2011. Subsequent to its publication, we received feedback confirming the need for and value of investment trustee education. Additional feedback, some provided by CFA Institute members, provided further understanding of the perspective, circumstances, and constraints that investment trustees face. Questions were asked and issues 
were raised that suggested the need for a more elaborated and nuanced discussion of certain topics and issues. Thus, this second edition.

Throughout the book, we use the term "trustee" broadly (and not in the legal sense of the word) to describe any person serving on a governing body who is charged with oversight and high-level supervision of investment assets. The governing body could be a pension investment committee at a corporation, an investment advisory council at a public retirement system, a board of trustees at an endowment fund, or something similar. If you are a member of such a group, then for our purposes, you are an investment trustee, regardless of your specific title.

An important aspect of this primer is the recognition that you do not have day-today responsibility for managing investment portfolios. Instead, you periodically receive reports from and meet with the staff or outside adviser of the fund that you oversee to discuss broad issues related to investment policy and performance results. Therefore, the challenges and opportunities you face are quite different from those of the staff who manage ongoing operations.

Over the years, we have been fortunate to have worked with trustees from many walks of life. Often, these individuals, although quite successful in their respective professions, possess little investment knowledge or experience. Yet, they take on responsibility for the oversight of investment assets that have a material impact on the welfare of their funds' beneficiaries. If you count yourself as one of these diligent laypeople, then you belong to the target audience for this book.

The audience also extends to the investment professionals who directly interact with you and to other parties who have a special interest in your fund. These people include the fund's staff, outside consultants, professional investment managers, actuaries, accountants, custodians, lawyers, and importantly, the beneficiaries of the fund. In most cases, the topics that we cover are familiar to investment professionals. Other interested parties may have little or no knowledge of them. Nevertheless, both groups stand to gain by taking your perspective and considering the learning curve and questions that you face, thereby gleaning useful insights as to how to work with you effectively.

Each of the trustees with whom we have worked earnestly desired to do a good job during their "watch." Just as you do, they wanted the fund to be in as sound or even better shape when they left the investment committee as it was when they joined it. Of course, this outcome often depends on the performance of the capital markets, something over which you have no control. But favorable investment markets have a way of masking uninformed and poor trustee oversight, and weak investment markets often expose deficiencies and magnify a trustee's fiduciary risk. Our objective is to help you understand important investment issues and ensure that appropriate philosophies, policies, processes, and people are in place so that the fund may succeed regardless of the investment environment. 


\section{Organization of the Book}

In this book, we focus on the primary subjects critical to your success as a trustee. The book is divided into "sessions" dealing with each of these topics. In each session, we present the material in the form of an overview that the chair of the fund's investment committee is providing to a new trustee.

Our conversation with the new trustee on each of the topics is followed by a session recap, or takeaway. Then, we list questions that we believe would be useful for the trustee to ask the investment committee chair, the staff, or the fund's outside advisers. Although these questions are not meant to be exhaustive, they do provide you with an opportunity to drill down into each session topic. New trustees are often uncomfortable asking questions of more experienced trustees, staff, or outside advisers. We want to assure you not only that the example questions (and others, of course) are appropriate to ask but also that other trustees, staff members, or outside advisers may not necessarily have ready answers. Thus, both parties can learn through intelligent questions.

We believe that to create and maintain a well-managed investment program, you and your fellow trustees should have, at a minimum, a solid grasp of the following foundational topics as they apply to your fund:

1. Governance structure-the responsibilities of the various types of decision makers within an investment program and how these decision makers relate to one another.

2. Investment policy-the procedures, guidelines, and constraints for decision making and management, with an emphasis on the trade-off between expected return and risk in setting the broad outlines of the fund's investment program.

3. Fund mission - the fund's reason for existence and the needs of the various stakeholders, starting with the fund's beneficiaries.

4. Investment objectives-investment outcomes, consistent with the fund's mission, that signal whether the investment program has been successful.

5. Investment risk tolerance-the extent to which trustees, as a body, are willing to accept the potential for significant losses in the pursuit of the fund's mission.

6. Investment assets - the definition and organization of the opportunity set of investments available to the fund and the various approaches to managing the fund's investments.

7. Defined contribution retirement plans - the recognition that plan participants, rather than the fund sponsor, bear the risk of the investment assets and hence investment trustees for these plans face a different set of responsibilities and issues from those faced by trustees for defined benefit retirement plans, endowments, and foundations. 
8. Performance evaluation-a regular assessment of the fund's outcomes relative to the fund's investment objectives, which reinforces the hierarchy of accountability, responsibility, and authority defined in the fund's governance structure.

9. Ethics in investing-considerations related to how trustees avoid perceived or actual conflicts of interest while fulfilling their investment program oversight duties.

In each session, our goal is to provide you with a broad overview of the particular foundational topic and how to drill deeper into that topic if you choose. At the end of the book, we include sample investment policy statements for an endowment fund, a defined benefit plan, and a defined contribution plan. Also, the book includes a glossary of investment terms and a list of further readings. We want to make a new or inexperienced trustee conversant in the substantive issues related to these topics. Armed with that basic knowledge, we believe that the dedicated investment trustee will be a more effective participant in committee deliberations. Our goal is to empower the thousands of investment trustees whose grasp of the finer points of the investment business may not always be strong to feel confident that they can effectively perform their oversight duties.

The complete book can be found at https://www.cfapubs.org/toc/rf/2017/2017/3.

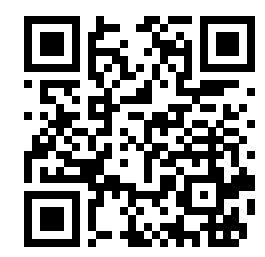

Use your mobile device to scan the QR code to go straight to the webpage. 


\section{EQUITY VALUATION: SCIENCE, ART, OR CRAFT?}

\section{by Frank J. Fabozzi, CFA, Sergio M. Focardi, and Caroline Jonas}

How can investors know whether the market price of a particular stock-or of stocks in general-is fair value? Fundamental analysts and fundamental active managers believe that it is possible to determine the intrinsic (fundamental) value of a company's stock by analyzing the company. Theoretically, fundamental value should indicate if a stock is under- or over-priced and, under the assumption of reversion to the mean, suggest profitable strategies. Studies, however, show that on average and over time, despite all the fundamental research, active traditional managers fail to outperform markets. Indeed, there is a pronounced trend away from actively managed funds and toward passive investments. Morningstar Manager Research reported that investors withdrew almost $\$ 264$ billion from actively managed US equity funds in 2016; for the same period, passively managed US equity funds saw net inflows of almost \$237 billion.

Although the trend to passive equity funds is particularly pronounced in the United States, it is also present in Europe, where passive equity funds now attract more net inflows than active equity funds, and in the Asia-Pacific region, where net inflows to passive strategies now almost match flows to active strategies.

This book explores a number of issues relative to equity valuation, in particular:

- Public stocks are traded in competitive markets and subject to the law of supply and demand: Is there really such a thing as an intrinsic (or fundamental) value of a stock? If yes, can we determine this value using the tools we presently have? Or can we determine only relative values?

- What about determining the value of hard-to-value assets, such as initial public offerings or private equity? What is the role of "hype", information asymmetry, or behavioral biases in determining the value of these assets? 
- Assuming that fundamental active analysts can estimate the intrinsic value of a stock and spot mispricings by comparing the intrinsic price to the market price, can they execute an advantageous trade that delivers value to the investor? What tools and heuristics do such analysts use and how effective are they?

- Do economic phenomena, such as quantitative easing and low-to-negative interest rates by central banks or corporate stock buybacks, distort market prices, taking them far from a stock's fundamental price? More in general, have these phenomena distorted entire markets, raising them to record highs?

- What is the equilibrium between the cost and the benefit of doing fundamental analysis, where the benefit is alpha or extra return to the investor?

- Does fundamental active management really play an important role in keeping markets (quasi) efficient?

- Will news streams, new data sources, new tools, or new technology not yet (widely) used allow fundamental managers to better estimate a stock's intrinsic value, thereby delivering on the promise to beat the market?

- Has the global investment universe changed so much that the role of fundamental analysis is no longer central? In other words, are there better ways to generate returns for investors than traditional value investing?

The book addresses these questions. It is based on a review of the literature and conversations with asset managers, chief investment officers at pension funds, academics, and other market players.

The complete book can be found at https://www.cfapubs.org/toc/rf/2017/2017/4.

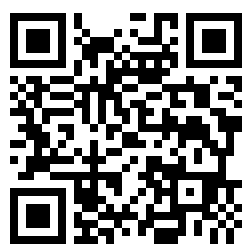

Use your mobile device to scan the QR code to go straight to the webpage. 


\section{HANDBOOK ON SUSTAINABLE INVESTMENTS: BACKGROUND INFORMATION AND PRACTICAL EXAMPLES FOR INSTITUTIONAL ASSET OWNERS}

\section{by Swiss Sustainable Finance Summary prepared by Sabine Döbeli and Christian Dreyer, CFA}

Over the course of more than 20 years, the advancement of sustainable investments has created a large and diverse offering that includes products and services for virtually every asset class, geographical region, and investment strategy. These investments have proven themselves to be comparable with conventional investment products in terms of risk and return, in many cases providing more-effective portfolio diversification. At the same time, they make an active contribution towards bringing the economy onto a more sustainable path.

There are several reasons why institutional investors consider sustainability aspects when making investments. The three main criteria are

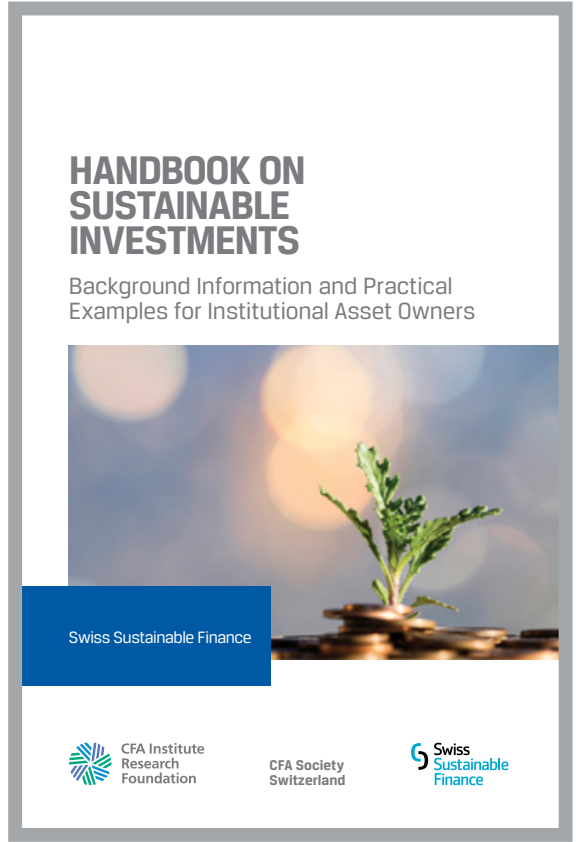

- complying with generally recognised international and national standards/norms or specific values defined by their own organisation within their investment activity,

- improving the risk/return profile of investments, and

- promoting sustainable development and business practices.

More and more investors who manage wealth for third parties on a fiduciary basis have added sustainability criteria to their investment policy for one or more of these reasons. 
Recently, new regulations governing sustainability have been introduced in many European countries. The Ordinance against Excessive Compensation in Listed Corporations (VegüV) was Switzerland's first bid to make active exercising of shareholder votes on specific themes obligatory for pension funds. Pressure from various stakeholders is steadily mounting. These include NGOs, who stress the responsibility of institutional investors, and members of pension funds, who want to see their assets invested in a responsible manner.

Despite the growing trend for regulation, self-regulation is still very important in sustainable investment. The need to define a sustainable investment policy in a selfdetermined manner-as well as being as flexible as possible in its implementation-has already encouraged a number of Swiss institutional investors to go down this route. Many others have only just started discussions at a top level to see whether, and how, such a step could be taken.

One thing is clear: Switzerland has already built up enormous expertise in the area of sustainable investments, and anyone embarking on that course will not be alone. The huge choice currently available might actually intimidate investors trying to come to grips with this topic for the first time. After all, it is not that simple to get a clear idea of the different approaches and decide which is most suited for a particular organisation.

This book, therefore, is designed to meet the growing demand for a clear overview of sustainable investments as practised today in Switzerland and elsewhere. The main target audience is representatives of such institutional investors as pension funds, insurance companies, foundations, and family offices that are looking to initiate a discussion about the implementation of a sustainable investment policy or have been instructed to develop such a policy. This publication is thus aimed not only at the foundation board of trustees but also at the heads of institutional investment companies, investment specialists in general, and people who deal with investment strategies as part of their supervisory role but are not actively involved in this area on a daily basis.

The book is organised into four parts:

Part 1: Sustainable Investments in Context describes the developments on this theme among institutional investors in Switzerland. One chapter examines the important question of the potential effect on the performance of an investment portfolio of applying sustainability criteria. The last chapter describes the regulatory situation in major European countries (including Switzerland).

Part 2: Different Approaches to Sustainable Investment and Specific Asset Classes is the main body of the publication. In this section, all the current approaches to sustainable investment are introduced and explained. In addition, specific sustainable asset classes that are becoming increasingly important are outlined. 
Part 3: Special Themes explores interdisciplinary topics that are highly relevant for all sustainable investments. This includes the question of how climate change-and the measures taken to combat it-affects investment portfolios and how these impacts can be rendered measurable. Another chapter examines the role that indices play for sustainable investment. Finally, the importance of transparent reporting for sustainable investment strategies is discussed.

Part 4: Steps to Implementation is perhaps the most important part of the book. In the manner of a cookbook, this lists the ingredients for defining and implementing a sustainable investment policy. All the key steps are described-from determining the main motivation to defining the investment policy and implementing the strategyand allocated to the various actors within an organisation.

Throughout the book, there are also a number of case studies providing insights into how sustainable investment strategies are implemented by various institutional investors. The examples include a number of pension funds (as well as one insurance company, a foundation, and a family office) and offer a varied picture of different approaches to implementing a sustainable investment policy.

Like every specialist field, sustainable investment has developed its own terminology, which often contains abbreviations (just to make things even more complicated). A short glossary at the end of the book explains the most important terms.

Taken as a whole, the book clearly shows that sustainable investments have evolved into a mature market. We hope you enjoy reading this publication and discovering the strategy that best suits your own organisation.

The complete book can be found at https://www.cfapubs.org/toc/rf/2017/2017/5.

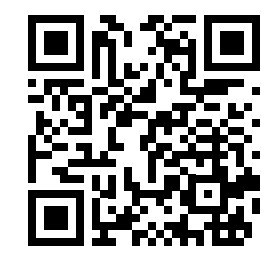

Use your mobile device to scan the QR code to go straight to the webpage. 


\section{LITERATURE REVIEW SUMMARIES}




\section{THE EQUITY RISK PREMIUM: A CONTEXTUAL LITERATURE REVIEW}

\section{by Laurence B. Siegel}

The equity risk premium, defined as the difference between the expected return on an equity index and the expected return on a "riskless" reference asset (such as Treasury bonds), is the most important variable in finance. Estimates of it are useful for asset allocation, security analysis, asset-liability management, long-range planning, capital budgeting, and many other purposes.

Neither the expected (total) return on equities nor the equity risk premium is directly observable in the marketplace the way a bond yield is. As a consequence, one has to estimate the equity risk premium (ERP) indirectly. The chief ways of doing so are the following:

1. By measuring the rate of return earned historically on equities and on the selected reference asset (usually Treasury bills or bonds), and assuming that the difference of those two rates, the historical ERP, will prevail in the future

2. By using a forecast model such as the dividend discount model, where the expected return on equities is assumed to equal the dividend yield plus the growth rate of dividends (one also sees variations involving earnings instead of dividends)

3. By discerning what excess rate of return (over the riskless rate) investors should require, given their behavior in other markets, for taking the risk of equities

These are sometimes referred to as the equilibrium, supply, and demand approaches respectively. The first method characterizes equilibrium because actual market results reflect the influence of both supply and demand. The second method asks what cash flows companies generate in support of the equity holder's claim and thus represents the supply side.

The demand approach has produced very low estimates of the ERP, completely at odds with experience. At this point it is of interest mostly to academics, although it remains a 
mystery why their approach should give a result so different from the other approaches when it is asking the same question.

\section{Prehistory of the ERP}

Edgar Lawrence Smith seemed to intuit the ERP in a 1924 book, wherein he presented evidence that stocks were the best investment asset for the long run. Researchers in the 1930s, 1940s, and 1950s typically used a dividend discount model (DDM) to estimate the expected returns on specific stocks, although they generally did not aggregate the stocks to form a market index nor did they subtract the expected bond or bill return to arrive at an ERP estimate.

\section{What Rate of Return Did Markets Provide?}

In a landmark pair of articles published in the Journal of Finance in 1976, Roger Ibbotson and Rex Sinquefield, working at the University of Chicago, measured the returns on the major US asset classes-stocks, bonds, and Treasury bills, plus CPI inflation (not an asset but a reference rate that can be used to convert nominal to real quantities). Their historical study period, 1926-1974, was long enough to include various types of bull and bear markets, a crash, and so forth, and thus in the authors' view, it embraced most of the event types that were likely to occur in the future.

Their estimate of the ERP, 5.4\%, updated annually in subsequent work, became the standard for quite some time. That number is the geometric mean of the difference between historical stock and intermediate-term Treasury bond total returns; the arithmetic mean is higher.

Ibbotson and Sinquefield hypothesized that investors conform their expectations to that which proves realizable over time, so they expected the future ERP to equal that of the past. To arrive at an expected total return for equities using this method, one adds the current riskless rate (in this case, the yield on an intermediate-term Treasury bond) to the ERP estimate.

This method is still widely used in the financial planning, brokerage, and securities sales communities. However, most academics and serious practitioners find that it gives too high a forecast, partly because historical returns incorporate a past increase in the price/ earnings (PE) multiple that cannot be repeated indefinitely into the future. 


\section{The Equity Premium Puzzle}

About 1985, two academics, Rajnish Mehra and Edward Prescott, "challenged the finance profession with a poser: the historical U.S. equity premium . . . is an order of magnitude greater than [is consistent with] the standard neoclassical paradigm of financial economics" (from the published abstract of Mehra's 2003 article). ${ }^{1}$ This "standard paradigm" is based on the idea that investors want assets that pay off when times are bad-but stocks, like bonds, pay off when times are good.

Thus, Mehra wrote in 2003, because "stocks and bonds pay off in approximately the same states of nature or economic scenarios ... they should command approximately the same rate of return. In fact, using standard theory to estimate risk-adjusted returns, ... stocks . . . should command, at most, a 1 percentage point return premium over bills."

That is the puzzle. What is the solution? A great many papers have been written, pointing out that stocks have much more risk than bonds over any time horizon with which an investor is likely to be concerned. A few researchers, especially Jeremy Siegel, however, believe stocks are safer than bonds over the very long run because they represent real economic assets that are more durable-less likely to be destroyed by war, hyperinflation, or other disasters-than the money promises made by governments to bondholders. This latter view has been borne out by hyperinflation episodes in pre-war Germany and other countries.

\section{Return of the Dividend Discount Model}

In the 1980s, in response to the high forecasts made using the Ibbotson and Sinquefield approach, a large number of researchers, both academics and practitioners, began to argue that the ERP could not be that high because the fundamental drivers of total return-dividend yields and the growth rate of dividends-did not support such forecasts. (A similar argument can be made using earnings instead of dividends.) One then subtracts the bill or bond yield from the DDM-based equity total return forecast to arrive at the expected ERP.

John Campbell and Robert Shiller did the pioneering work on DDM-based approaches in the 1980s, with Eugene Fama and Kenneth French, Robert Arnott and Peter Bernstein, Clifford Asness, and William Bernstein and Robert Arnott providing a great deal of supporting evidence over the subsequent two decades. Many of these researchers agreed on an ERP around 3\%, much lower than the Ibbotson-Sinquefield estimates. Their primary arguments are the following:

\footnotetext{
${ }^{1}$ Rajnish Mehra, “The Equity Premium: Why Is It a Puzzle?” Financial Analysts Journal, vol. 59, no. 1 (January/ February 2003): 54-69.

${ }^{2}$ Mehra, “The Equity Premium," 56.
} 
- Historical returns are too high as a forecast of future returns because the valuation (say, P/E) of the market rose considerably over the historical period.

- Only forward-looking variables such as expected dividend yields and expected growth are relevant anyway.

- The DDM is a theoretically correct way of assessing the expected return on an asset.

- In the long run, earnings and dividend growth cannot be faster than the growth rate of the economy; otherwise, corporate profits would eventually consume all resources, leaving nothing for labor, government, and so forth. This growth rate has averaged $2.5 \%$ in real terms, and one must further reduce this number to account for "dilution," that is, the creation of new shares to fund new firms and to expand the capital base of existing ones.

Thus, investors should expect the future ERP to be lower than the historical ERP. Because bill and bond yields are also now at historically low levels, the expected total return on equities is considerably lower at this time than it was on average over the historical periods usually studied.

DDM-based estimates of the ERP are currently the dominant estimates. Even Ibbotson Associates (part of Morningstar Inc.) has dropped the future-equals-past forecasting method in favor of a type of DDM.

\section{A Reasonably Current Forecast}

A 2011 CFA Institute Research Foundation article by Richard Grinold, Kenneth Kroner, and myself brought these various threads together and set forth an ERP estimate based on a variant of the DDM. The authors added three components of equity total return: (1) income, consisting of the dividend yield adjusted for buybacks and net new issues; (2) earnings growth; and (3) repricing, representing any change in the P/E that an analyst might expect, converted to an annual rate.

The results, as of 2011 , were $1.98 \%$ for the income return, $5.05 \%$ for earnings growth (based on real earnings growth of $1.8 \%$, equal to the historical real growth rate of GDP, plus an inflation forecast), and zero for repricing. The expected total return on US equities is thus $7.03 \%$, from which a $3.4 \%$ yield on 10 -year Treasury bonds is subtracted to arrive at a 3.6\% ERP forecast. A similar method can be used for non-US markets.

Because 2011 is a long time ago in market terms, an update would be useful. The income return has not changed much, nor is there a compelling reason to change the real earnings growth number. However, inflation rates and bond yields have gone down. 
Prudent analysts might also want to subtract some amount for repricing, because the $\mathrm{P} / \mathrm{E}$ is higher than it was in 2011 and is also higher than its historical average by a considerable margin.

The complete book can be found at

https://www.cfapubs.org/toc/rflr/2017/12/1.

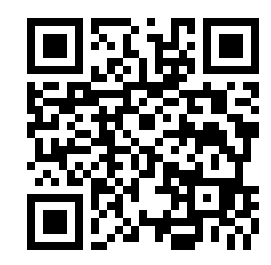

Use your mobile device to scan the QR code to go straight to the webpage. 


\section{BRIEFS SUMMARIES}




\section{IMPACT OF REPORTING FREQUENCY ON UK PUBLIC COMPANIES}

\section{by Robert C. Pozen, Suresh Nallareddy, and Shivaram Rajgopal}

Corporate executives have long decried the undue emphasis on short-termism-defined as maximizing corporate profits in the next quarter. Instead, most corporate executives say that they want to make corporate investments from a long-term perspective-defined as enhancing corporate value over a period of three to five years (Rappaport 2006).

This concern about favoring short-termism over long-termism has now spread to institutional investors (Perrin 2016). In an open letter, Lawrence Fink, CEO of BlackRock, warned US companies that they may be harming their long-term value by capitulating to pressures from activist hedge funds to increase dividends or share buybacks in the short term (Fink 2015).

In response, commentators and regulators have proposed a broad range of remedies to curb short-termism in corporate America (Pozen 2014). These proposals include, but are not limited to, higher taxes on short-term trading, faster filings for groups acquiring more than $5 \%$ of a company's voting stock, reduced say by institutional investors in managerial decisions, and increased voting rights for shareholders based on the length of their holding period.

Of particular interest to CFA Institute members are the calls for public companies to issue earnings reports on a semiannual rather than quarterly basis. This proposal was put forth by a distinguished American lawyer (Benoit 2015) and was discussed at a recent US SEC hearing (SEC 2015). Even former US Secretary of State Hillary Clinton has expressed concern about the adverse effects of quarterly reporting on the long-term profitability of American corporations (Udland 2016).

Over the last decade or so, Europe has engaged in a "natural experiment" on the effects of reporting frequency. In its 2004 Transparency Directive, the European Commission announced that by early 2007 all EU member states must require their public companies to issue interim management statements (IMS) on a quarterly basis (European 
Parliament and Council 2004). However, in its 2013 amendments to the directive, the European Commission reversed direction by removing this requirement (European Commission 2013).

We undertook this study to assess the actual impact of the frequency of company reporting on UK public companies. Specifically, this study looked at the effects on UK corporate investments and capital markets of moving to required quarterly reporting in 2007 and then dropping this requirement in 2014.

Most importantly, this study found that the initiation of required quarterly reporting in 2007 had no material impact on the investment decisions of UK public companies. As discussed in Section 2A, the study measured this impact by examining, before and after these changes in reporting requirements, the companies' capital expenditures; spending on research and development; and spending on property, plant, and equipment.

By contrast, the initiation of mandatory quarterly reporting in 2007 was associated with significant changes in other areas. An increasing number of companies published more qualitative than quantitative quarterly reports and gave managerial guidance about future company earnings or sales. At the same time, there was an increase in analyst coverage of public companies and an improvement in the accuracy of analyst forecasts of company earnings.

When quarterly reporting was no longer required of UK companies in 2014, less than $10 \%$ stopped issuing quarterly reports (as of the end of 2015). Again, there was no statistically significant difference between the levels of corporate investment of the UK companies that stopped quarterly reporting and those that continued quarterly reporting. However, there was a general decline in the analyst coverage of stoppers and less of such decline for companies continuing to report quarterly.

Companies that stopped quarterly reporting manifested two characteristics: They were relatively small by market capitalization, and they did not issue managerial guidance during the period of mandatory quarterly reporting. Energy companies were the most prevalent stoppers, followed by utilities.

This brief is organized into four parts, plus a final section on "Conclusions and Implications":

1. We first review the UK context for quarterly financial reports before the regulatory change in 2007.

2. We summarize the effects from 2007 onwards on companies initially switching to quarterly reporting in 2007. 
3. We review the key forces behind the move away from required quarterly reporting in 2014.

4. We summarize the effects on companies that stopped issuing quarterly reports beginning in 2014 .

The complete book can be found at

https://www.cfapubs.org/toc/rfbr/2017/3/1.

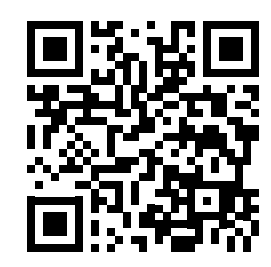

Use your mobile device to scan the QR code to go straight to the webpage. 


\section{FINANCIAL RISK TOLERANCE: A PSYCHOMETRIC REVIEW}

\section{by John E. Grable}

The concept of risk, and the specific evaluation of risk attitudes and risk taking, has a long and colorful history. Bernstein (1996) wrote the seminal review of the history of risk, pointing out that the concept of risk being related to outcome probabilities goes back more than 800 years. The first major breakthrough in thinking about risk, however, occurred in 1738 when Daniel Bernoulli used his knowledge of probabilities to uncover an important relationship between wealth and risk taking. He concluded that individuals prefer to take less risk and that they demand greater potential returns to engage in risky activities. Bernoulli's work laid the foundation for the development of expected utility theory and modern portfolio management principles. However, challenges to assumptions imbedded in the standard utility function began to emerge shortly after World War II. The notion that individuals, when dealing with financial decisions, always make rational choices across scenarios could not be fully supported empirically.

The first systematic risk attitude measurements were developed in the late 1950s. Kogan and Wallach (1964), for example, created the choice dilemma questionnaire, which remained a standard paradigm for the next 30 years. Their assessment tool was based on asking respondents to indicate the lowest probability of success required to undertake a risky choice in 12 scenarios dealing with a multitude of contexts. The data demonstrated that choice dilemmas did not do a consistently good job at explaining or predicting an individual's behavior (Kamalanabhan, Sunder, and Vasanthi 2000), particularly in the domain of investment and financial planning.

As behavioral economics and behavior finance gained traction as fields of study, researchers and investment professionals justifiably began to question both traditional models of economic behavior and the tools used to evaluate client attitudes. A general skepticism regarding existing frameworks led to the publication of a handful of validated financial risk-tolerance assessment instruments in the 1980s (MacCrimmon and Wehrung 1984; The American College 1994). Since that time, dozens (if not 
hundreds) of tools have emerged to evaluate an individual's willingness to engage in a financial behavior in which at least one outcome is both unknown and potentially negative. Nearly all of these instruments have been designed by practitioners and firms. Unfortunately, few risk-tolerance assessment tests have been created using recognized test theory principles.

This review provides financial analysts, investment professionals, and financial planners with an examination of how financial risk-tolerance tests can and should be evaluated. The review begins by clarifying terms related to risk taking. A broad overview of two important measurement terms, validity and reliability, follows. The review concludes with examples for practice.

The complete book can be found at https://www.cfapubs.org/toc/rfbr/2017/4/1.

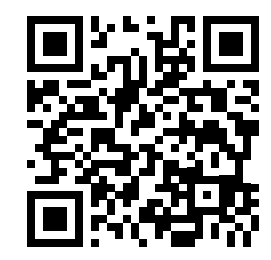

Use your mobile device to scan the QR code to go straight to the webpage. 


\section{FINTECH AND REGTECH IN A NUTSHELL, AND THE FUTURE IN A SANDBOX}

\section{by Douglas W. Arner, Jànos Barberis, and Ross P. Buckley}

Interaction between finance and technology is not novel. The abacus is a testament to the long-standing relationship between the two. But the 2008 global financial crisis (GFC) represented a pivotal moment that separated prior phases of the development of financial technology (FinTech) and regulatory technology (RegTech) from the current paradigm.

Today, FinTech has entered a phase of rapid development marked by the proliferation of startups and other new entrants, such as IT and ecommerce firms that have fragmented the financial services market. This new era presents fresh challenges for regulators and highlights why the evolution of FinTech necessitates a parallel development of RegTech. In particular, regulators must develop a robust new framework that promotes innovation and market confidence, aided by the use of regulatory "sandboxes."

Currently in its second stage of development, RegTech is being used by both institutions and regulators to address increasingly cumbersome compliance processes. But regulators have yet to unlock the transformative potential of RegTech. We argue that certain RegTech developments today are highlighting the path toward another paradigm shift, which will be typified by a reconceptualization of the nature of financial regulation. This "RegTech 3.0" will involve a regulatory approach that is as datacentric as the markets it monitors. 
The complete book can be found at https://www.cfapubs.org/toc/rfbr/2017/3/4.

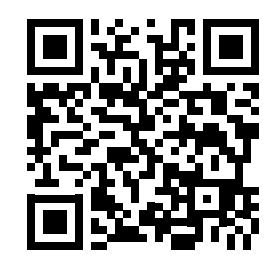

Use your mobile device to scan the QR code to go straight to the webpage. 


\title{
NEW VISTAS IN RISK PROFILING
}

\author{
by Greg B. Davies
}

Risk profiling is fraught with misunderstandings that lead to ill-advised approaches to determining investment suitability. These include

- using observed behaviour to determine risk tolerance;

- optimising for "behavioural" risk attitudes, rather than helping clients mitigate and control them;

- eliciting risk tolerance on subcomponents of overall wealth;

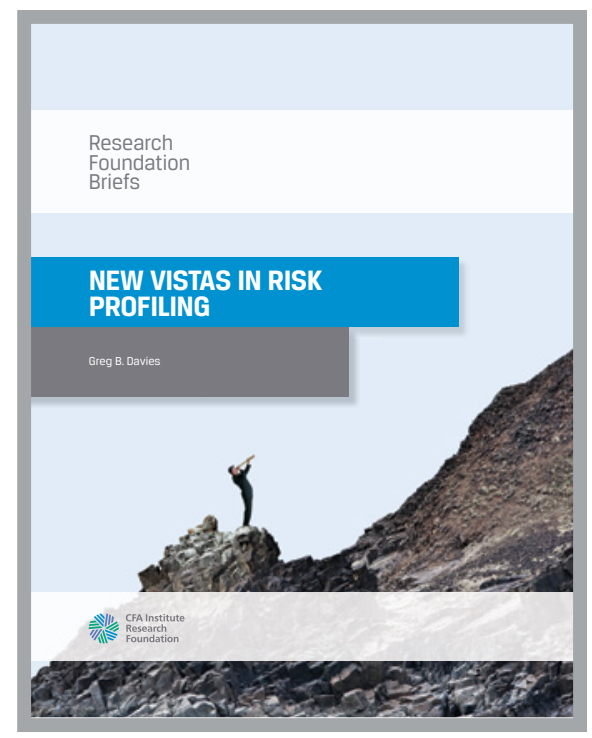

- using overengineered and unstable approaches for measuring risk tolerance;

- putting far too little effort into understanding risk capacity; and

- using "required" returns as inputs to the investment solution.

To get past these, we need a crystal clear understanding of the crucial distinctions between risk tolerance (an investor's stable, reasoned willingness to take risk in the long term), behavioural risk attitudes (the unstable, behavioural, short-term willingness to take risk exhibited through an investor's actions), and risk capacity.

Risk tolerance reflects the level of risk we should deliver for a client over the long term. Behavioural risk attitudes, in contrast, are transient and context-dependent preferences that result in poor outcomes if we mistake them for risk tolerance. They are not attitudes we should want in the driver's seat for our long-term portfolio optimisation. The role of suitability is to steer investors toward better outcomes, not replicate (and optimise for) all the silly things they do already.

Risk capacity is vital because the risk investors are willing to take might not be risk they are able to take. Risk capacity chiefly concerns investors' ability to meet future liabilities, so there is an essential connection between risk capacity and both (1) a holistic view of the client's current circumstances and (2) goal-based investing. Risk capacity is the vital pivot 
turning information from the wealth planning process into a measure of the appropriate risk level for the investment process.

For most investors, risk capacity is vastly more important than risk tolerance, and yet industry debate unnecessarily centers on how to better measure the latter. Unfortunately, the greater complexity of risk capacity means it is easy for those with vested interests in particular views to obfuscate the debate. A series of simplified investor cases can help strip away this complexity to extract the essential features and exact role of each of the three components.

If we genuinely want to determine the right amount of risk, it is not sufficient just to measure risk tolerance. It is also not sufficient to supplement this with a narrow model of risk capacity. We also need to help people understand, articulate, and dynamically adapt their future goals, plans, and aspirations over their journey. Effective goal-based investing is necessary to truly find the appropriate risk level.

But the best investment solution is not just about establishing the theoretically "right" solution; at least as important are other behavioural risk attitudes that affect anxiety over the journey. Emotional comfort is never the goal of investing, so portfolio construction should seek to help investors mitigate and manage these attitudes rather than pander to them by "optimising" for them. Often that means moving slightly away from the "best" solution if by doing so we purchase a big reduction in anxiety efficiently and cheaply-that is, with as little deviation from the solution that fits their long-term risk profile as possible. The best solution needs to be both sufficiently efficient and sufficiently comfortable: Do not let the best be the enemy of the good.

The flip side of the lack of attention given to risk capacity and behavioural risk attitudes is an unnecessary tendency to search for ever more sophisticated ways of eliciting risk tolerance, which are in many cases misguided. The gap lies not in how risk tolerance is measured but in how it is used. A simple, well-designed measure, used well, is hard to beat.

That said, there are promising new vistas using big data, observed behavioural patterns, and machine learning, but these should be used to understand behavioural risk attitudes, not risk tolerance. Profiling should provide an opportunity for investors to learn about their attitudes, emotions, and biases, and in doing so, it should help them prepare for the anxiety of the journey. The more this can be done using investors' own past behaviour and their specific financial situation and goals, the more effectively it will help them govern their future behaviour.

Possibly the most exciting new vista is not about what is measured; it is about when and how the data are collected and used. Advances in technology, data analytics, and behavioural design can blur current rigid distinctions between profiling, suitability, and client engagement. 
Every engagement point is an opportunity to enrich the profile. Every change in the profile is an opportunity to sharpen the overall solution. And every change to the solution is an opportunity to identify new valuable engagement opportunities. Risk profiling ideally becomes part of a never-ending dialogue between investor and adviser, constantly updating to changes in circumstances and preferences, creating a profiling process as a digital decision prosthetic to supplement and enhance the essential human side of investing.

To progress, we should focus on developing dynamic models of risk capacity and tools to truly help investors understand and articulate their own goals. We should concentrate much more on how we use this knowledge. And we should stop treating profiling as a point-in-time activity and instead ensure that suitability adjusts dynamically to meet constantly changing needs.

The ultimate new vista in risk profiling is that it becomes impossible to separate from goalbased suitability and from effective client engagement.

The complete book can be found at https://www.cfapubs.org/toc/rfbr/2017/3/5.

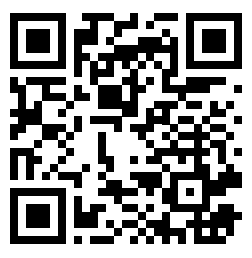

Use your mobile device to scan the QR code to go straight to the webpage. 


\section{ASIAN STRUCTURED PRODUCTS}

\section{by Angel Wu and Clarke Pitts}

Structured products are financial instruments designed and created to afford investors exposure (to something) through a derivative contract. The underlying asset can be an equity price, an interest rate, an exchange rate, an index, a credit spread, a commodity price-anything, in fact, for which there is an existing financial market.

The structured products industry is so big and so diverse that it is helpful to break it down into three parts.

- Privately placed and individually negotiated transactions involving one investor or a very small number of investors. Such transactions are typically executed through medium-term notes.

- Products sold through syndication by such retail networks as banks, brokerages, financial advisers, and insurance companies.

- Products that are actively traded on exchanges or with market makers, constituting the fastest-growing segment.

The choice of instrument is predicated on such considerations as tax efficiency and convenience. Some popular structured products are:

- Target redemption forward-an example is provided for the USD/CNY instrument.

- Accumulator/decumulator-an example is provided of the popularity in Hong Kong and Singapore, for both onshore and offshore investors in other Asian markets.

- Autocallable notes-an example is provided for the Nikkei 225.

The structured products industry is large enough and complicated enough that it should be examined by anyone involved or interested in finance and capital markets. The sums involved are comparable to those invested in hedge funds, yet these businesses are largely ignored by the press, the public, and even practitioners. 
The complete book can be found at https://www.cfapubs.org/toc/rfbr/2017/3/6.

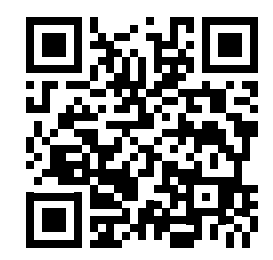

Use your mobile device to scan the QR code to go straight to the webpage. 



\section{MULTIMEDIA SUMMARIES}




\section{INTERVIEW WITH MICHAEL FALK}

Research Foundation author Michael Falk discusses his new book, Let's All Learn How to Fish... to Sustain Long-Term Economic Growth, with Morningstar's John Rekenthaler on 25 October 2016.

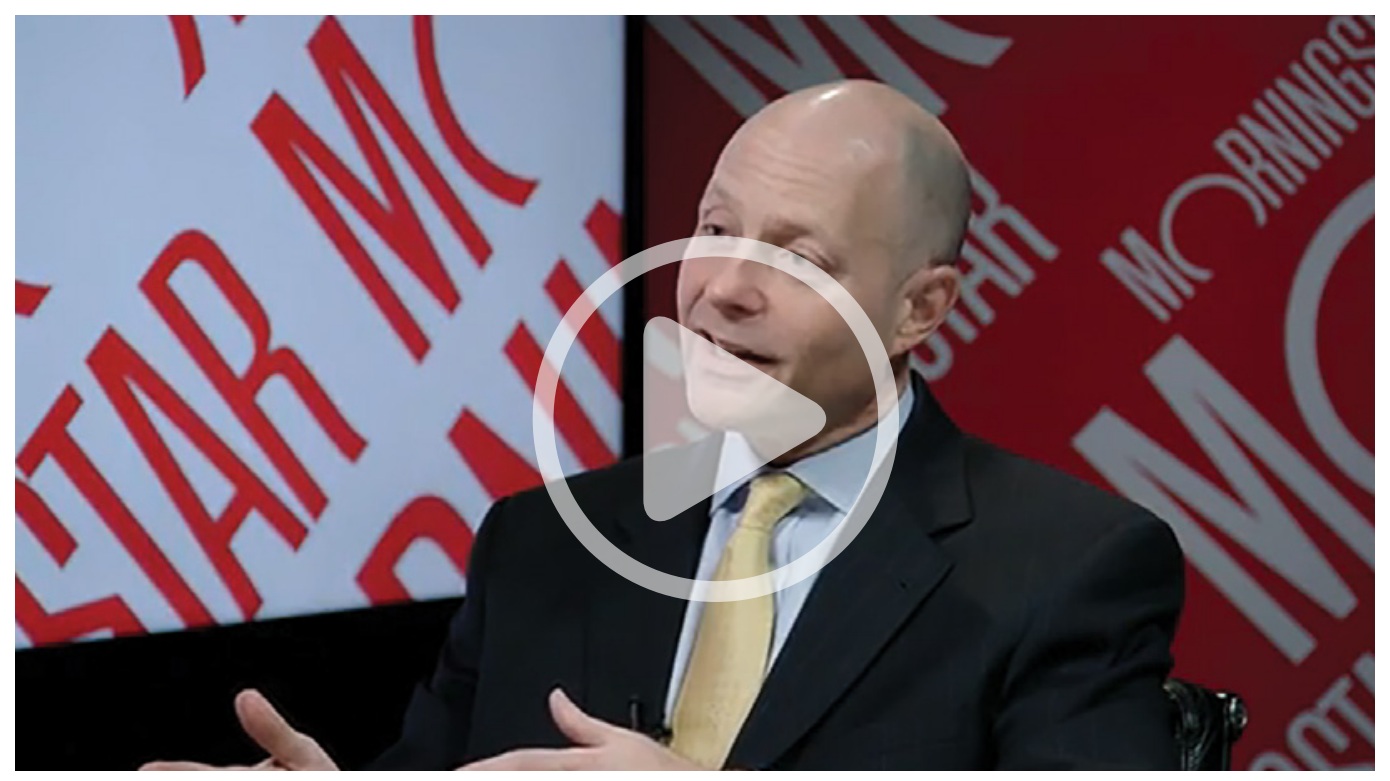

To view the video, visit:

http://www.morningstar.com/cover/videocenter.aspx?id=777852\&lineup=STOCKS 


\section{WORKSHOP FOR THE PRACTITIONER SUMMARIES}




\section{LET'S ALL LEARN HOW TO FISH... TO SUSTAIN LONG-TERM ECONOMIC GROWTH}

\section{Michael S. Falk, CFA}

This session from the 2017 CFA Institute Annual Conference discusses the following points:

- The costs of agedness could be more than $10 x$ the 2008 recession.

- Demographics do not have to be destiny; we have choices about policies that have an impact on workers and productivity.

- We need a culture that ushers in a new ERA (from Entitlement to Responsibility and with Appreciation) of sustainable, long-term economic growth.
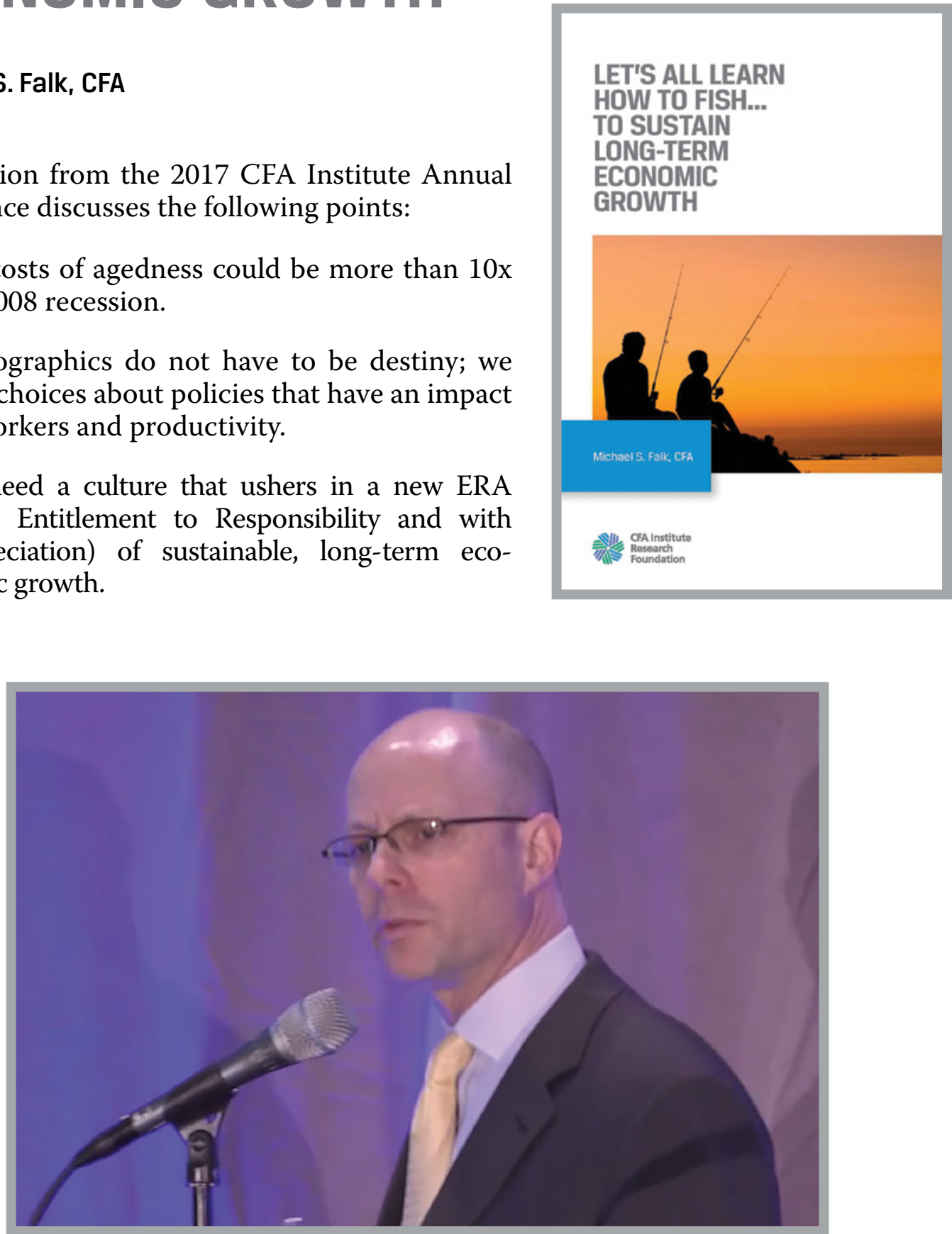
The complete book can be found at http://www.cfapubs.org/toc/rf/2016/2016/2.

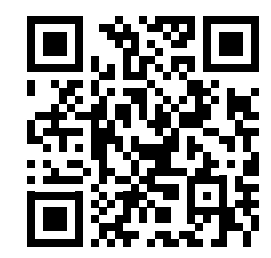

Use your mobile device to scan the QR code to go straight to the webpage. 


\section{FINANCIAL MARKET HISTORY: REFLECTIONS ON THE PAST FOR INVESTORS TODAY}

\section{David Chambers and Elroy Dimson Co-editors \\ October 2016}

In a session at the Research Foundation Workshop during the 2017 CFA Institute Annual Conference, co-editors David Chambers and Elroy Dimson discuss their recent book on the history of the financial markets.

Since the 2008 financial crisis, a resurgence of interest in economic and financial history has occurred among investment professionals. The monograph, Financial Market History, discusses some of the lessons drawn from the past that may help practitioners when thinking about their portfolios. The monograph is edited by David Chambers and Elroy Dimson, the academic leaders of the Newton Centre for Endowment Asset Management at the University of Cambridge.

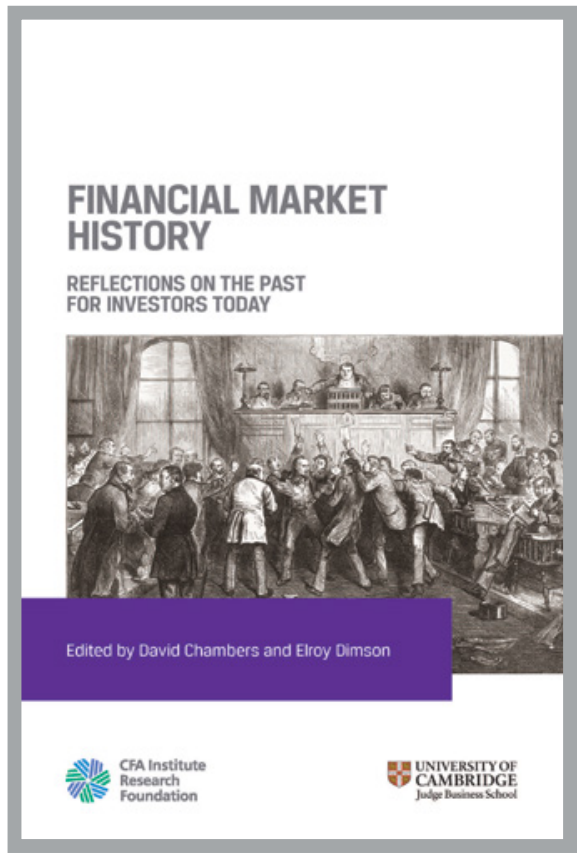

Some investment practitioners have long understood the benefit of learning from our financial past. For example, Russell Napier, in his book Anatomy of the Bear, and Andrew Smithers and Stephen Wright, in their book Valuing Wall Street, use financial history to inform and guide their investment strategies. Many other excellent publications would repay any practitioner who wishes to gain a deeper understanding of why financial markets have developed in the manner they have over the last several hundred years. These include, to name but a few, Niall Ferguson's The Ascent of Money, William Goetzmann's and Geert Rouwenhorst's The Origins of Value, Raghuram Rajan's and Luigi Zingales's Saving Capitalism from the Capitalists, and William Goetzmann's recently published Money Changes Everything.

Collection of the essays in Financial Market History has been supported by CFA Institute Research Foundation, CFA Society United Kingdom, and others. The monograph brings together a series of chapters from leading academics in historical finance. 
Their shared motivation is to examine a wide range of subjects that they believe are particularly relevant for investors today.

One of the major ways in which financial history contributes to investment practice is by providing long-run series of data on different asset classes. Elroy Dimson, Paul Marsh, and Mike Staunton summarize the long-run global evidence on the risk and return characteristics of such traditional asset classes as equities, bonds, bills, and exchange rates. Long-run return series span the broadest possible range of historical market conditions and are necessary for investors to understand likely future investment outcomes. Antti Ilmanen's essay complements this analysis by examining the time-varying properties of stocks. In particular, he considers how sensible it is to make use of long-run data series to try to time entry into and exit from markets. Jan Annaert, Frans Buelens, and Angelo Riva discuss some of the pitfalls to be avoided when assembling or using historical asset price data, especially equity and bond data. The temptation to simply download historical data in modeling risk and return, without thinking about the quality of the data and the care with which return series have been compiled, is to be avoided at all costs. Olivier Accominotti discusses the returns to two common currency-trading strategies, namely, carry and momentum. The tendency is to think that modern currency trading began after the collapse of Bretton Woods in the 1970s, but the foreign exchange market first emerged in its modern-day form in 1919. It seems we were largely unaware that currencies were actively traded through most of the 1920s and 1930s. Christophe Spaenjers provides investors with a fascinating insight into other assets that can be found in portfolios of high-net-worth individuals: real estate, collectibles, and precious metals and diamonds. Much academic work has been undertaken in recent years to collect historical prices of some of these assets, and we now have a better sense of their long-run performance characteristics.

Modern stock exchanges trace their origins back to Amsterdam in the early 17th century. Larry Neal's essay considers the origins and development of the most important stock market to emerge through the 19th century, the London Stock Exchange. How the LSE chose to organize itself had implications for the subsequent innovations in the way stocks were traded. Furthermore, some of the issues raised today by the emergence of electronic exchanges would have been familiar to the stock exchanges of more than a century ago, especially concerns about the liquidity with which stocks can be traded on the exchange. Caroline Fohlin's chapter offers a fascinating insight into how liquidity improved on the New York Stock Exchange in the early 20th century as technology improved, and she highlights how particular trading structures influence information flows and ultimately market liquidity. Carsten Burhop and David Chambers survey the long-run historical evidence about IPOs in the world's major stock markets. Their discussion addresses whether three phenomena-underpricing, the IPO cycle, and longrun underperformance-that are observed in modern markets existed in earlier times.

Stock markets and bubble episodes are frequently mentioned in the same breath. William Goetzmann reminds us that although bubbles insert themselves deeply into the investor psyche, they are relatively infrequent. He examines the frequency of large, 
sudden run-ups in stock prices since 1900 and concludes that the chances of the market giving back its gains following a doubling in value are only about $10 \%$. In other words, based on the history of the 20th century, only a small fraction of stock market booms ever go sour and turn into bubbles. Eugene White provides investors with a survey of the major bubble episodes, emphasizes the particular role played by irrational exuberance, and highlights the most important takeaways for investors to consider when the next bubble comes around. Charles Goodhart notes that financial crises usually arise when asset bubbles financed through bank credit expansion run their course. Prior to the middle of the 20th century, it was often a combination of an equity bubble with bank credit expansion that led to such a crisis; more recently, however, the key interaction has been between real estate boom/busts and credit expansion. Goodhart goes on to discuss the range of potential cures for such crises that have been offered but concludes that the achievement of a financial-crisis-free economy will remain elusive.

Financial innovation has been an important feature of financial market development over the centuries. Geert Rouwenhorst's essay on early financial contracts is a reminder that not all innovative security designs survive and that we can learn from those that do not as well as those that do. Tom Nicholas's contribution focuses on a particularly successful innovation in the United States, namely, venture capital. He describes the origins and development of high-tech venture investing in the post-1945 period and the factors that led to its success. Janette Rutterford and Leslie Hannah examine one of the most significant financial innovations in modern finance, namely, the institutionalization of securities investment via the rise of insurance companies, mutual funds, and pension funds.

This monograph is not intended to be exhaustive. Much important work by other eminent scholars has been omitted because of space limitations. Furthermore, as Barry Eichengreen's essay highlights, new frontiers in financial history are being opened up in the wake of the 2008 financial crisis. The hope of the editors is that this volume will persuade more practitioners that a detailed knowledge of the past can be worthwhile in tackling the investment challenges of the future.

The complete book can be found at http://www.cfapubs.org/toc/rf/2016/2016/3.

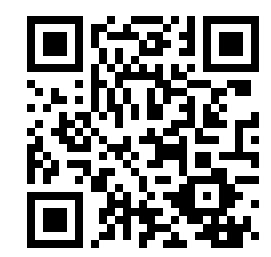

Use your mobile device to scan the QR code to go straight to the webpage. 


\section{AWARDS AND RECOGNITION}




\section{JAMES R. VERTIN AWARD}

The James R. Vertin Award is presented periodically to recognize individuals who have produced a body of research notable for its relevance and enduring value to investment professionals. This award was established in 1996 to honor James R. Vertin, CFA, for his outstanding leadership in promoting excellence and relevancy in research and education.

\section{Vertin Award Winner}

\section{William Bernstein}

William Bernstein is a neurologist and co-founder of investment management firm Efficient Frontier Advisors. He has also written several titles on finance and economic history, including The Birth of Plenty (on the economic growth inflection of the early 19th century) and A Splendid Exchange (a wide-angle look at the history of world trade). A third history book, Masters of the Word, explores the effects of access to technology on human relations and politics. Mr. Bernstein has contributed to the peer-reviewed finance literature and written for several national publications, including the Wall Street Journal.

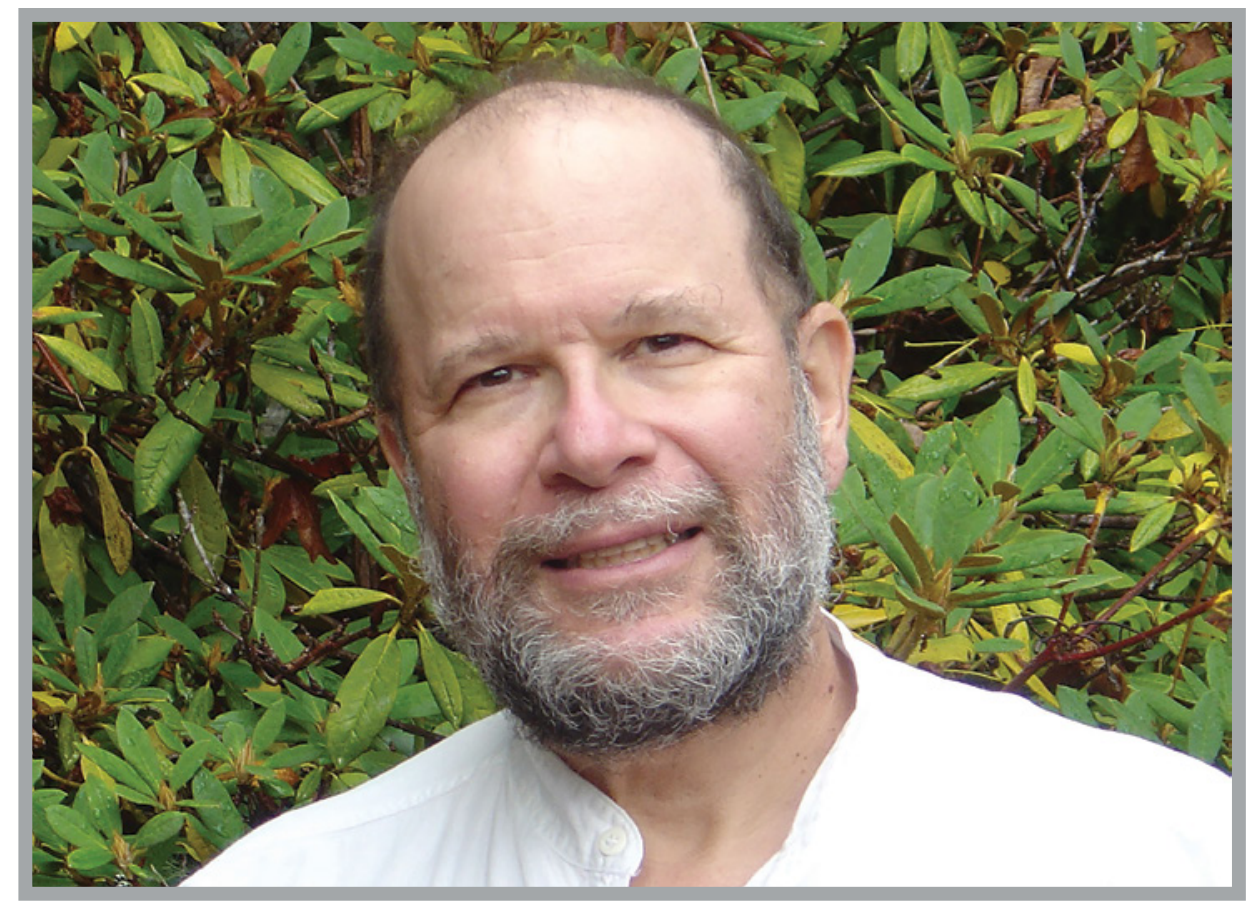




\section{Past Vertin Award Winners}

2016 Terry Odean

2015 Frank J. Fabozzi, CFA

2014 Kenneth R. French

2013 Richard C. Grinold

2013 Ronald N. Kahn

2012 Elroy Dimson

2010 Roger Clarke

2009 Robert Shiller

2008 Keith Ambachtsheer

2007 Campbell R. Harvey

2006 Clifford S. Asness

2005 Andrew W. Lo

2004 Edwin J. Elton

2004 Martin Gruber

2003 Barr Rosenberg

2002 William L. Fouse, CFA

2001 Rex A. Sinquefield

2001 Roger G. Ibbotson

2000 Peter L. Bernstein

1998 Martin L. Leibowitz

1997 Jack L. Treynor

1996 William F. Sharpe 


\section{RESEARCH FOUNDATION SOCIETY AWARD}

The Research Foundation Society Award is an annual award to the CFA Institute member society or societies that do the best job of using Research Foundation content in an activity, product, or service. The goal of the award is to build a strong, effective working relationship between societies and the Research Foundation.

Beginning in 2017, the award is granted to the society that has the best

- activity,

- content, or

- website design.

Some current Research Foundation programs that have evolved out of the Research Foundation Society Award include the following:

- Research Foundation content in society newsletters and on society websites

- Research Foundation author events and Research Foundation book distribution

- Research Foundation content distributed in company, university, and regulator outreach efforts

- Research Foundation content translations and creation of a book club with author conference call

- Research Foundation Research Challenge adviser presentation and Research Foundation book distribution

- Research Foundation board meeting hosting and creation of a society library with Research Foundation books

\section{Award Winners}

- CFA Society Brazil (best website design)

- CFA Montréal (best content)

- CFA Society New York (best activity) 


\section{Award Winners}

No award issued because of a change in the timing of the Society Leaders Conference.

\section{Award Winners}

- CFA Society Cleveland

- CFA Society Finland

- CFA Society France

- CFA Society Los Angeles

- CFA Society Milwaukee

- CFA Society Pakistan

- CFA Society Sydney

\section{Award Winners}

- CFA China

- CFA Society San Francisco

- Indian Association of Investment Professionals

- CFA Society Philadelphia (Encouragement Award ${ }^{1}$ )

\section{Award Winners}

- CFA Society Barbados

- CFA Society Hawaii

- CFA Society Pakistan

- CFA Society Italy

\footnotetext{
${ }^{1}$ The Encouragement Award is granted to a society whose efforts with the Research Foundation are commendable but not quite extensive enough to receive the Society Award.
} 
- CFA Society Emirates

- CFA Society Toronto

- CFA Society France (Encouragement Award)

\section{Award Winners}

- Boston Security Analysts Society

- CFA Society Argentina \& Uruguay

- CFA Society Buffalo

- CFA Society Bulgaria

- CFA Society Rochester

- CFA Society Seattle

The Research Foundation also extends a special thanks to societies that have hosted, or will be hosting, our trustee board meetings:

- CFA Society Toronto (Spring 2013)

- CFA Society San Francisco (Fall 2013)

- CFA Society Los Angeles (Spring 2014)

- CFA Society Minnesota (Spring 2015)

- New York Society of Security Analysts (Fall 2015)

- CFA Society Dallas/Fort Worth (Spring 2016)

- CFA Montréal (Fall 2016)

- CFA Society United Kingdom (Spring 2017)

- CFA Society Washington, DC (Fall 2017)

- CFA Society Mexico (Spring 2018)

- CFA Society Philadelphia (Fall 2018) 


\section{RESEARCH FOUNDATION LEADERSHIP CIRCLE}

The Research Foundation Leadership Circle honors investment professionals whose outstanding commitment and contributions have benefited the Research Foundation over an extended period of time. The Research Foundation is honored to recognize the following members of the Leadership Circle:

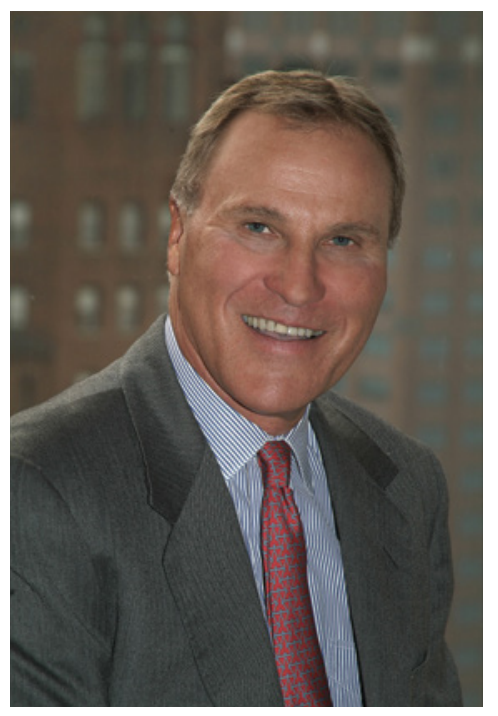

Gary Brinson, CFA

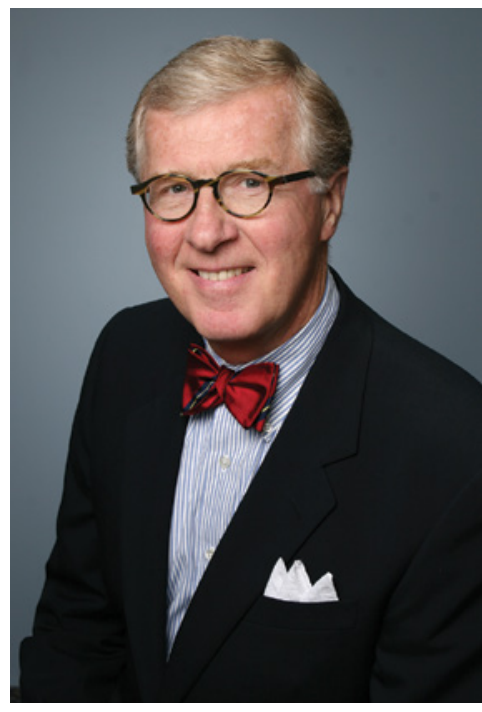

Fred Speece, CFA

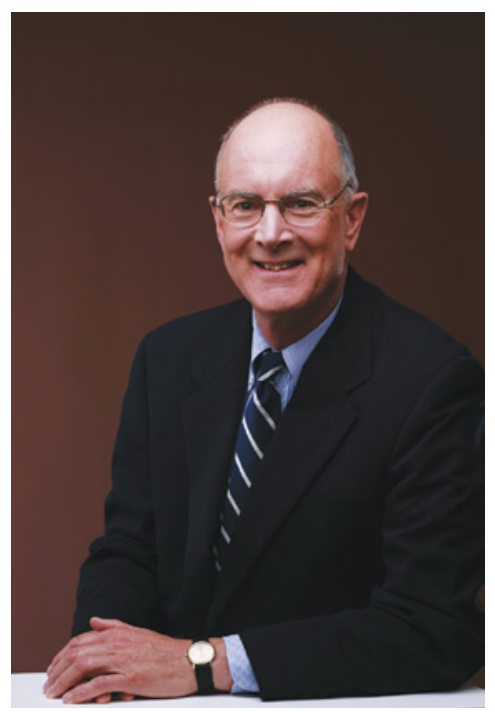

George Noyes, CFA

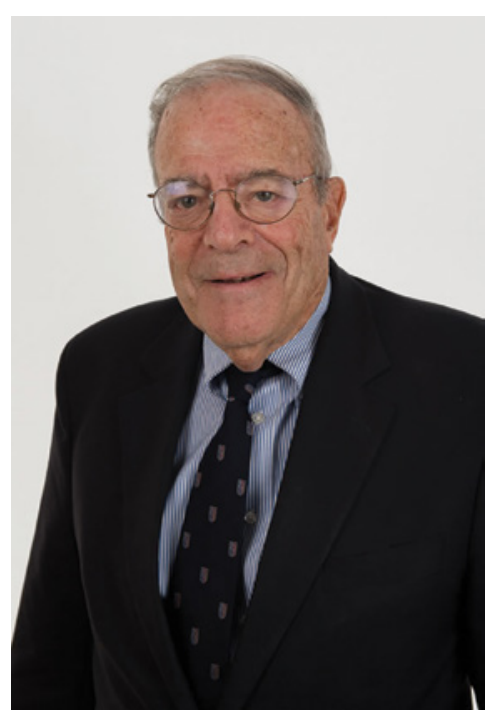

Walter Stern, CFA

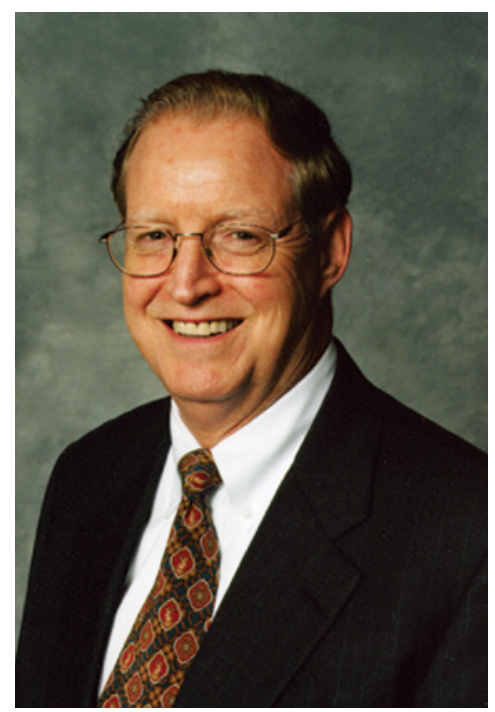

Frank Reilly, CFA

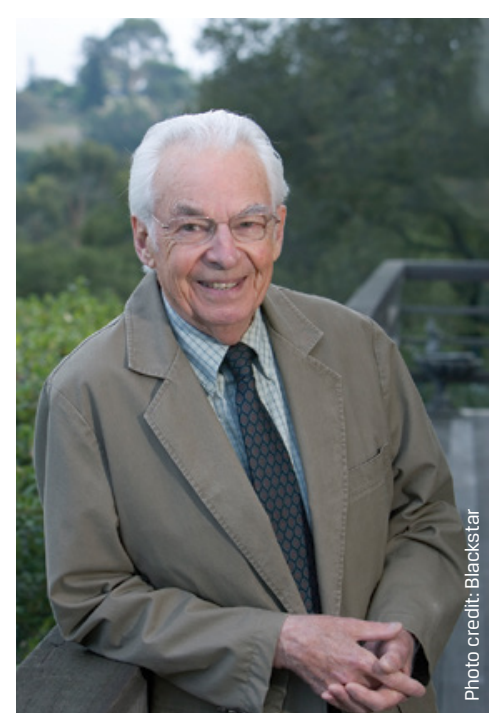

James R. Vertin, CFA 



\section{RECENT PUBLICATIONS}




\section{RECENT PUBLICATIONS FROM THE RESEARCH FOUNDATION ARCHIVE}

\section{6}

\section{Books}

Factor Investing and Asset Allocation: A Business Cycle Perspective (December)

Vasant Naik, Mukundan Devarajan, Andrew Nowobilski, Sébastien Page, CFA, and Niels Pedersen

This monograph draws heavily on the vast body of knowledge that has been built by financial economists over the last 50 years. Its goal is to show how to solve real-life portfolio allocation problems. We have found that using a broad range of models works best. Also, we prefer simple over complex models. We believe that simplicity and modularity lend substantial robustness to investment analysis. Importantly, the framework presented provides several of the "missing links" in asset allocation-for example, the links between asset classes and risk factors, between macroeconomic views and expected returns, and ultimately between quantitative and fundamental investing.

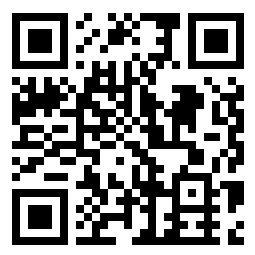


Financial Market History: Reflections on the Past for Investors Today (December)

David Chambers and Elroy Dimson

Since the 2008 financial crisis, a resurgence of interest in economic and financial history has occurred among investment professionals. This book discusses some of the lessons drawn from the past that may help practitioners when thinking about their portfolios. The book's editors, David Chambers and Elroy Dimson, are the academic leaders of the Newton Centre for Endowment Asset Management at the University of Cambridge in the United Kingdom.

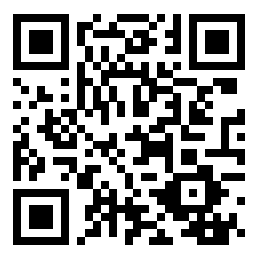

Let's All Learn How to Fish... to Sustain Long-Term Economic Growth (May)

Michael S. Falk, CFA

Today's economic growth challenges will become greater in the future because of the world's aging population, fertility trends and current levels, and current entitlement policies. Those challenges could be overcome, however, with thoughtful public policies and a culture that fosters responsibility and appreciation. This book reconsiders what makes us "healthy, wealthy, and wise." It focuses on how we might reimagine health care, retirement, and education policies to usher in a new ERA (from Entitlement to Responsibility with Appreciation) of sustainable long-term economic growth.

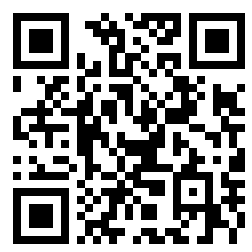




\section{Literature Reviews}

Technical Analysis: Modern Perspectives (November)

Gordon Scott, CMT, Michael Carr, CMT, and Mark Cremonie, CMT, CFA

Supply and demand are cornerstones of economics and the interaction of these forces is believed to explain price changes in all freely traded markets. Scarcity tends to result in increased prices and abundance generally leads to lower prices. In financial markets, technical analysis provides a framework for informing investment management decisions by applying a supply and demand methodology to market prices. Technical analysts employ a disciplined, systematic approach that seeks to minimize the impact of behavioral biases and emotions that could adversely affect investment performance. Analysts employ ratio analysis, comparative analysis and other techniques that are similar to the tools developed to analyze financial statements.

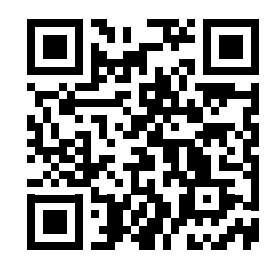

\section{Briefs}

"Gender Diversity in Investment Management: New Research for Practitioners on How to Close the Gender Gap" (September)

Rebecca Fender, CFA, Renée Adams, Brad Barber, and Terrance Odean

We've completed the largest ever survey of investment management professionals on the subject of gender diversity.

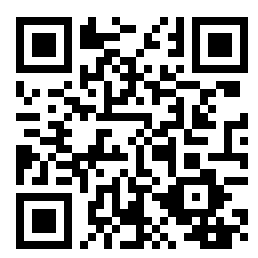


"Portfolio Structuring and the Value of Forecasting" (August)

Jacques Lussier, CFA, Andrew Ang, PhD, Mark Carhart, CFA, Craig Bodenstab, CFA, Philip E. Tetlock, Warren Hatch, CFA, and David Rapach

Drawing from a CFA Montréal event, this analysis of factor investing reviews types of factors and risk premiums as well as the value of forecasting, including issues with accuracy and improving efficiency.

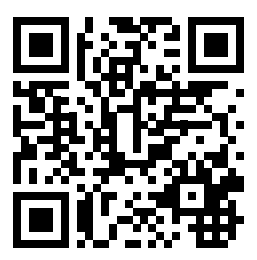

"Overcoming the Notion of a Single Reference Currency: A Currency Basket Approach" (April)

Giuseppe Ballocchi, CFA, and Hélie d'Hautefort

Wealthy families with a global footprint have liabilities and financial objectives in multiple currencies. To manage their currency risk, it is necessary to abandon the notion of a single reference currency in favor of a customized basket of currencies. We introduce the Global Reserve Currency Index, a useful proxy for the world currency.

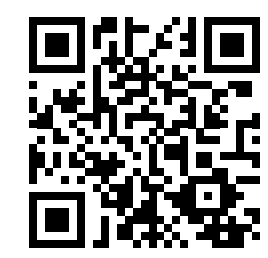


"Annuities and Retirement Income Planning" (February)

Patrick J. Collins, CFA

Annuitization is one asset management strategy for retirees seeking to secure lifetime income. The US annuity marketplace offers a variety of annuity contracts, including single premium annuities, advanced life deferred annuities, variable annuities with lifetime income guarantee riders, and ruin contingent deferred annuities. Advisers seeking to provide guidance to clients in or near retirement can benefit by understanding (1) the arguments both for and against annuitization and (2) how a client's interests might be best represented in the marketplace. Important annuity contract provisions are highlighted and briefly discussed so the adviser can become more familiar with retirement-planning options.

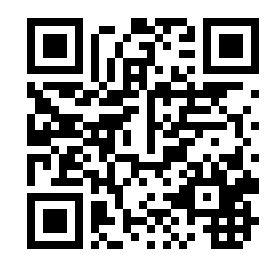

"Risk Profiling through a Behavioral Finance Lens" (February)

Michael Pompian, CFA

This piece examines risk profiling through a behavioral finance lens. Advisers can classify clients into behavioral investor types to help determine what kind of investment plan they should recommend. With a better understanding of behavioral finance vis-à-vis risk taking, practitioners can enhance their understanding of client preferences and better inform their recommendations of investment strategies and products.

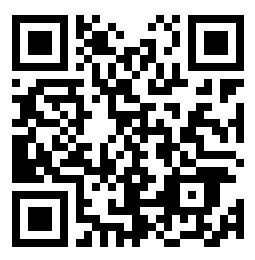




\section{5}

\section{Books}

The Industrial Organization of the Global Asset Management Business (November) Ingo Walter

The dynamics of the asset management business are complex and geographically diverse. Products and vendors compete within and across markets and often shade into each other. Regulation can differ dramatically according to financial systems and functions. Here are discussed the major asset management sectors-pension funds, mutual funds, alternative investment vehicles, and private wealth management. Despite the complexity of the industry, common threads run through the discussion-growth, risk, and cost-that cannot be ignored by asset managers hoping to be sustainably profitable. What is required to excel includes distribution in leading markets, product breadth and consistency, global money management expertise, and capital strength. Also needed are technological capability, marketing and customer service skills, defensible pricing, low-cost production, and a strong brand. All these characteristics must be rooted in an affirmative culture with cohesive senior management and a talented and motivated staff.

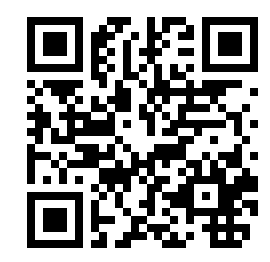

Trading and Electronic Markets: What Investment Professionals Need to Know (October)

Larry Harris, CFA

The true meaning of investment discipline is to trade only when you rationally expect that you will achieve your desired objective. Accordingly, managers must thoroughly understand why they trade. Because trading is a zero-sum game, good investment discipline also requires that managers understand why their counterparties trade. This book surveys the many reasons why people trade and identifies the implications of the zero-sum 
game for investment discipline. It also identifies the origins of liquidity and thus of transaction costs, as well as when active investment strategies are profitable. The book then explains how managers must measure and control transaction costs to perform well.

Electronic trading systems and electronic trading strategies now dominate trading in exchange markets throughout the world. The book identifies why speed is of such great importance to electronic traders, how they obtain it, and the trading strategies they use to exploit it. Finally, the book analyzes many issues associated with electronic trading that currently concern practitioners and regulators.

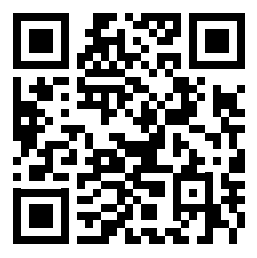

A Comprehensive Guide to Exchange-Traded Funds (ETFs) (May)

Joanne M. Hill, Dave Nadig, and Matt Hougan

Exchange-traded funds (ETFs) have become in their 25-year history one of the fastest growing segments of the investment management business. These funds provide liquid access to virtually every financial market and allow large and small investors to build institutional-caliber portfolios. Yet, their management fees are significantly lower than those typical of mutual funds. High levels of transparency in ETFs for holdings and investment strategy help investors evaluate an ETF's potential returns and risks. This book covers the evolution of ETFs as products and in their uses in investment strategies. It details how ETFs work, their unique investment and trading features, their regulatory structure, how they are used in tactical and strategic portfolio management in a broad range of asset classes, and how to evaluate them individually.

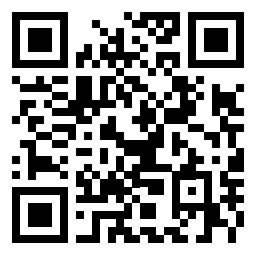


Geopolitics for Investors (March)

Pippa Malmgren

Geopolitical issues have a profound effect on investment strategies and results. Investors inevitably must balance risk and reward. Geopolitics can bring both risks and opportunities, large and small, onto the investment landscape. The question is, How much time and effort can be devoted to this particular task? Prediction is nearly impossible but preparedness is attainable and desirable. Fund managers and investors need to ask whether preparedness is best achieved through scenario planning, by including geopolitics as one of many drivers of the investment strategy, or by changing the investment team or the information sources and services that the team uses. As always, markets represent diverse interests and abilities. Some investors will find a way to add geopolitics to their investment scenarios and to profit from it. Others will take comfort in knowing that they were not alone in utterly ignoring geopolitics. This monograph offers some core ideas about how to think about the subject. These ideas may prove useful as geopolitics returns to the investment landscape with increasing force.

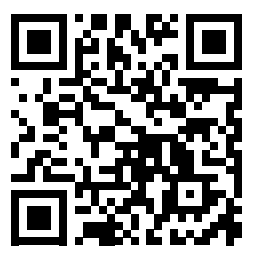

\section{Literature Reviews}

Longevity Risk and Retirement Income Planning (November)

Patrick J. Collins, CFA, Huy D. Lam, CFA, and Josh Stampfli

The past 50 years have seen an abundance of research on retirement planning and longevity risk. Reviewed here is the academic side of the research and its varied viewpoints and nuances. The evolution of retirement risk models, retirement portfolio problems and solutions, and annuities are some of the many topics covered.

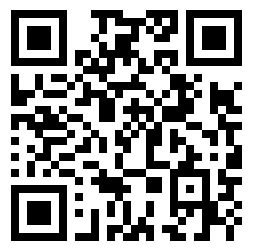




\section{Briefs}

"Investor Risk Profiling: An Overview" (April)

Joachim Klement, CFA

The current standard process of risk profiling through questionnaires is highly unreliable and typically explains less than $15 \%$ of the variation in risky assets between investors-mostly because the questionnaires focus on socio-economic variables and hypothetical scenarios. The existing research in risk profiling shows, however, that several factors can provide more accurate and reliable insights into the risk profile of investors. Among these factors are the lifetime experiences an investor has had, the financial decisions made in the past, and the influence of family and friends as well as advisers. By using these factors, practitioners can get a better understanding of their clients' preferences in order to recommend suitable investment strategies and products.

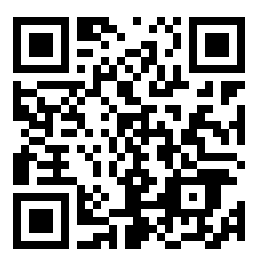




\section{4}

\section{Books}

The New Economics of Liquidity and Financial Frictions (December)

David Adler

The New Economics of Liquidity and Financial Frictions is a book about a new branch of economics that is largely a synthesis of macro and finance. In many ways, it is a radical departure from the older, frictionless approach still prevalent in economic textbooks and most of academia. This book provides a new understanding and approach to asset pricing, risk measurement and management, central banking policy, and the overall working of today's economy, including questions of financial stability.

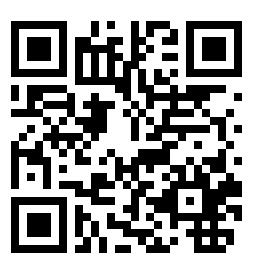

Investment Management: A Science to Teach or an Art to Learn? (May)

Frank J. Fabozzi, CFA, Sergio M. Focardi, and Caroline Jonas

Following the 2007-09 financial crisis, mainstream finance theory was criticized for failing to forecast the market crash, which resulted in large losses for investors. Has our finance theory, which many consider an idealization that does not take reality into account, failed investors? Do we need to reconsider the theory and how it is taught (and practiced)? This book explores current critiques of mainstream theory and discusses implications for the curricula of finance programs as well as for practitioners. In so doing, the authors integrate a review of the literature supported by conversations with finance professors, asset managers, and other market players.

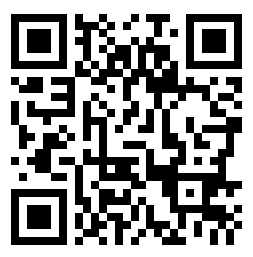


Environmental Markets: A New Asset Class (January)

Richard L. Sandor, Nathan J. Clark, Murali Kanakasabai, and Rafael L. Marques

Population growth, industrialization, and urbanization in the past 200 years have resulted in local, national, and global pollution of our environment. Markets, when designed properly, can be a powerful agent to combat this pollution. Environmental finance is thus the art and science of using economic incentives, financial tools, and market mechanisms to achieve desired environmental outcomes.

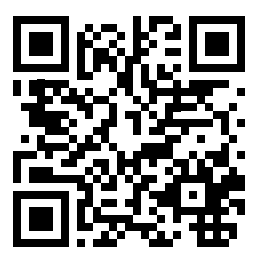

\section{Literature Reviews}

Islamic Finance: Ethics, Concepts, Practice (November)

Usman Hayat, CFA, and Adeel Malik, PhD

Islamic economic thought and finance are rooted in Islamic ethics. Their ideals and means are not, however, exclusive to Islam. The principles of Islamic finance emphasize market-based risk-sharing modes of financing that promote assets and enterprise, deploy finance in service of the real economy, and facilitate redistribution of wealth and opportunity. Modern Islamic financial practices, however, privilege legal form over economic substance, which creates an expectations gap between Islamic finance's theory and practice. In the wake of the global financial crisis of 2007-2008, the ideas underlying Islamic finance appeal to those more concerned with the broader impact of finance on society.

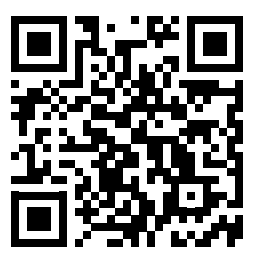


Investment Professionals and Fiduciary Duties (September)

Marianne M. Jennings

The distinction between brokers and investment advisers has become increasingly blurred over the past 30 years. In a 2011 study, the US SEC recommended that there be one uniform standard for both broker/dealers and investment advisers. In addition, all investment professionals could benefit from some standards. Through a review of market history, literature, and general principles from fiduciary relationships, some simple concepts emerge that could help investment professionals navigate the conflicts of interest that are inevitable given the often blended roles that they play in the financial markets.

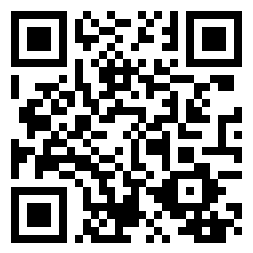

The Principal-Agent Problem in Finance (March)

Sunit N. Shah

The relationship between a principal and the agent who acts on the principal's behalf contains the potential for conflicts of interest. The principal-agent problem arises when this relationship involves both misaligned incentives and information asymmetry. In asset management, factors contributing to the principal-agent problem include managers' compensation structures and investors' tendency to focus on short-term performance. In the banking industry, myriad principal-agent relationships and complex instruments provide a fertile breeding ground for incentive conflicts, many of which were highlighted by the recent financial crisis.

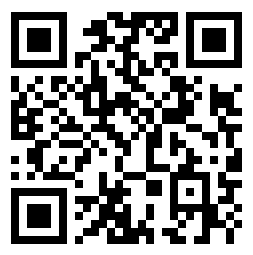




\section{RESEARCH GROUP CONTENT}

\section{FUTURE OF FINANCE}

The Future of Finance initiative is a long-term global effort to shape a trustworthy, forward-thinking investment profession that better serves society. It provides the tools to motivate and empower the world of finance to promote fairness, improved understanding, and personal integrity. Its success is driven by ongoing input from volunteers and an advisory council of prominent leaders. In partnership with CFA societies, we seek to amplify our mission to uphold the highest standards of ethics, education, and excellence. During 2017, the Future of Finance initiative released two publications"Future State of the Investment Profession" and "Focus on Fees."

Meanwhile, the Future of Finance initiative continues to support society-driven initiatives, including the following:

- Putting Investors First campaign-held in April and May to raise awareness about the importance of investor rights and encourage investment professionals to better serve and protect investors. In 2017, 112 societies participated globally.

- Women in Investment Management initiative-activities that seek to attract, retain, and promote women in the investment management profession.

\section{Future of Finance Publications}

\section{Future State of the Investment Profession}

The investment management industry is facing significant disruptive forces, internally and externally. This study discusses megatrends, such as shifting demographics, changing regulatory environments, current movements in digitization and commoditization, and new technology-centric business models that will necessitate changes in the industry. Those who lead the industry-or aspire to lead it-will need new skills and vision to succeed.

We outline four possible scenarios for the next 5-10 years, describing both what these changes might look like and ways to influence the future state of the profession for the best possible outcomes. 


\section{Focus on Fees}

This guide explains the importance of fees and fee structures for individual investors. The CFA Institute Statement of Investor Rights says individuals have the right to "an explanation of all fees and costs charged to me, and information showing these expenses to be fair and reasonable."

Fees are a tool to align incentives, and pros and cons of four common structures are discussed, including potential conflicts of interest. "Focus on Fees" also provides a sample of the effect of fees on a portfolio over time and a list of questions to consider when evaluating fees related to professional investment advice. This guide helps investors ensure their interests are being put first.

\section{FINANCIAL ANALYSTS JOURNAL}

In 2017, a journey began to transition the Financial Analysts Journal from a print-centric publication to a useful and impactful digital tool that continuously publishes content that can be integrated into the workflow of investment practitioners and serves as a platform for bringing new research and ideas into the marketplace.

To support this vision, we will be guided by three goals:

\section{Emphasize practical relevance}

- Publish articles that clearly communicate the applicability of the research and ideas

- Develop practice-focused companion content and resources

\section{Stimulate member engagement}

- Enhance and optimize the print and digital delivery channels

- Personalize user experience of content discovery and access

\section{Raise brand awareness}

- Tighten the Financial Analysts Journal brand identity and association with the CFA Institute brand

- Increase visibility and impact in the marketplace 
To achieve these goals, we have implemented two changes:

- Switched to a rolling 12-month open access model for peer-reviewed articles

- Reduced the frequency of print publication to quarterly (we will continue to publish the same number of articles each year, posting them online ahead of print)

\section{Financial Analysts Journal Publications}

\section{7}

\section{"Inefficiencies in the Pricing of Exchange-Traded Funds"}

Antti Petajisto

A novel approach that controls for stale pricing of the underlying assets could be useful in detecting mispricings of exchange-traded funds and in creating active trading strategies that exploit these mispricings.

\section{"Global Equity Fund Performance: An Attribution Approach"}

David R. Gallagher, Graham Harman, Camille H. Schmidt, and Geoffrey J. Warren

On average, global equity managers beat their benchmarks by 1.2\%-1.4\% a year before fees. The major strength of successful managers is the ability to select stocks that beat their local markets.

\section{"Are Cash Flows Better Stock Return Predictors Than Profits?"}

Stephen Foerster, CFA, John Tsagarelis, CFA, and Grant Wang, CFA

A way to transform indirect method cash flow statements to isolate cash flows from recurring, value-creating activities can help improve stock return predictions.

"Fundamental Indexing in Global Bond Markets: The Risk Exposure Explains It All" Lidia Bolla, CFA

A fundamental indexing approach to government bonds can outperform a marketvalue-weighted index. But the higher returns are largely derived from greater exposure to fixed-income risk factors.

\footnotetext{
"When Carry Goes Bad: The Magnitude, Causes, and Duration of Currency Carry Unwinds"

Michael Melvin and Duncan Shand

A model that helps estimate the length of currency carry drawdowns could be valuable in controlling carry-related losses and improving investment performance.
} 
"Balancing Professional Values and Business Values"

John C. Bogle

"How Do Investors Compute the Discount Rate? They Use the CAPM"

Jonathan B. Berk and Jules H. van Binsbergen

"Accounting's Tower of Babel: Key Considerations in Assessing Non-GAAP Earnings"

Jack T. Ciesielski, CFA, and Elaine Henry, CFA

"Active Share and the Three Pillars of Active Management: Skill, Conviction, and Opportunity"

Martijn Cremers

Active Share has become a buzzword among investors. But it only gives them meaningful information when selecting active funds if it is considered in tandem with fees, manager conviction, and opportunity.

"Facts about Formulaic Value Investing"

U-Wen Kok, CFA, Jason Ribando, CFA, and Richard Sloan

Value-investing strategies based on simple ratios, such as the book-to-market ratio, are ubiquitous. But they do not appear to be good substitutes for strategies employing a more comprehensive approach to identifying underpriced securities.

\section{"Factor Investing in the Corporate Bond Market"}

Patrick Houweling and Jeroen van Zundert, CFA

Multi-factor bond funds are a rarity. But they can avoid the long periods of underperformance seen in single-factor funds, reduce tracking error, and, in general, allow investors to better control their exposures.

"Mononationals: The Diversification Benefits of Investing in Companies with No Foreign Sales"

Cormac Mullen and Jenny Berrill

Are investors getting their international diversification all wrong? The evidence is that buying shares in foreign companies that sell only to their local markets is a better way to diversify equity portfolios.

"Funding Ratio Peaks and Stalls"

Martin L. Leibowitz, Stanley Kogelman, and Anthony Bova, CFA 
“The Long-Run Drivers of Stock Returns: Total Payouts and the Real Economy” Philip U. Straehl and Roger G. Ibbotson

The "total payout model," which includes buybacks as well as dividends, appears to be more predictive of stock prices than the traditional price-to-earnings and dividend yield approaches used by analysts.

\title{
"Do Social Responsibility Screens Matter When Assessing Mutual Fund Performance?"
}

Marie Brière, Jonathan Peillex, and Loredana Ureche-Rangau

Does ESG investing add or subtract value from investment portfolios? Neither, this study suggests. So, investors can match index performance while "doing good" for the environment and society.

"News vs. Sentiment: Predicting Stock Returns from News Stories"

Steven L. Heston and Nitish Ranjan Sinha

Most stockpickers follow news about company performance. They may be surprised to know that the impact of positive news on prices is fleeting, while negative news has a longer-lasting effect.

\section{"Stick to the Fundamentals and Discover Your Peers"}

Jens Overgaard Knudsen, Simon Kold, and Thomas Plenborg

Selecting stocks for comparative analysis on the basis of industry classification alone could lead to wrong conclusions. Choosing peers that have similar fundamental drivers could lead to more accurate analysis.

\section{"History Is Repeating Itself: Get Ready for a Long Dry Spell"}

Ramzi Ben-Abdallah and Michèle Breton

An unusual set of market circumstances could reduce the effectiveness of hedging with interest rates using T-bond futures. In addition, short-sellers of some Treasury issues could face a squeeze.

\author{
"An Interview with Nobel Laureate Harry M. Markowitz" \\ Mark Kritzman, CFA, and Harry M. Markowitz \\ “Time to Change Your Investment Model" \\ Feng Gu and Baruch Lev
}




\section{"Estimating Time-Varying Factor Exposures"}

Andrew Ang, Ananth Madhavan, and Aleksander Sobczyk

Is there a reliable way to gauge the skill of actively managed mutual fund managers when factor loadings are dynamic? Rolling time-series regressions can give flawed estimates. This study is one of the first to use cross-sectional risk characteristics to estimate time-varying factor loadings, with promising results.

\section{"Global Equity Country Allocation: An Application of Factor Investing"}

Timotheos Angelidis and Nikolaos Tessaromatis

Despite their growing popularity, factor-based portfolios face implementation challenges. Constructing factor portfolios from country indexes, rather than from individual stocks, can reduce costs and increase capacity without damaging their performance.

\section{"Optimal Tilts: Combining Persistent Characteristic Portfolios"}

Malcolm Baker, Ryan Taliaferro, and Terence Burnham

Is it logical to seek the best combination of investment factors by risk/return characteristics alone? Excluding factors that are hard to implement and costly to trade could lead to improved selection.

\section{"Reducing Sequence Risk Using Trend Following and the CAPE Ratio"}

Andrew Clare, James Seaton, Peter N. Smith, and Stephen Thomas

Sequence risk can dramatically affect retirement income. But decumulating investors do not have to resign themselves to the accident of their birth date. This study suggests that by following a simple trend-following strategy, investors can substantially cut sequence risk while maintaining or improving their returns. 
